\title{
Careers, Labor Market Structure, and Socioeconomic Achievement ${ }^{1}$
}

\author{
Seymour Spilerman \\ Russell Sage Foundation
}

\begin{abstract}
The objective of this paper is to develop the notion of the career as a strategic link between structural features of the labor market and the socioeconomic attainments of individuals. In the first section we review the treatment of careers in the occupational sociology literature and consider limitations of the traditional conceptualization. In the second section the main features of career lines, their structures and reward trajectories, are described. In conjunction with this discussion, the virtues and drawbacks of several strategies for delineating career lines from empirical data are addressed. In the next section we sketch the determinants of career-line structures as they reside in industry organization and labor market composition. In the concluding pages we consider the implications of a labor market overlaid with career lines for investigations of the socioeconomic-achievement process.
\end{abstract}

There are many points of convergence in the literatures of occupational sociology, industrial sociology, organization theory, and labor economics. In this paper we employ the perspectives of these subdisciplines to illuminate the nature of work careers; as a second concern, we discuss the relevance of the career concept to a comprehension of the socioeconomicattainment process. By a "career line" or "job trajectory" we shall mean a work history that is common to a portion of the labor force. ${ }^{2}$ Our focus, therefore, is on a life-cycle phenomenon, typically a sequence of jobs, rather than on the employment situations of individuals at a given time or at a particular age. Elucidating the properties of these job sequencestheir entry portals, number of constituent positions, availability of transfer options to alternative career lines, and shapes of their returns in earnings,

\footnotetext{
1 The work reported here was supported in part by funds granted to the Institute for Research on Poverty at the University of Wisconsin by the Office of Economic Opportunity pursuant to the Economic Opportunity Act of 1964 and in part by a grant from the Brookdale Institute of Gerontology and Adult Human Development, Jerusalem. I would like to thank Robert Kaufman for his assistance with the computations and Burton Singer, David Featherman, and Ross M. Stolzenberg for their comments on an earlier draft. The conclusions are the sole responsibility of the author. An earlier version of this paper was presented at the Conference on Occupational Careers Analysis, Greensboro, North Carolina, March 26-28, 1976, which was sponsored by the Social Science Research Council's Committee on Work and Personality in the Middle Years. 2 Following Slocum (1966, p. 6), we use the term "career" to refer to an individual's job history, and the terms "career line" and "job trajectory" to denote an empirical regularity (i.e., structural feature) in the labor market.
} 
status, and work satisfaction as a function of age-constitutes the principal task of career-line analysis.

Jobs are viewed quite differently from this life-cycle perspective in the socioeconomic-achievement literature. In that paradigm (Blau and Duncan 1967; Duncan, Featherman, and Duncan 1972; Jencks et al. 1972) the emphasis is on assessing the effects of characteristics prior to labor force entry (e.g., intelligence, education, father's SES) on an individual's occupational standing and earnings in later life. Little attention is given in that literature, though, to the linkages which exist among jobs; in short, work positions are not viewed as components of coherent career lines. Ignoring the textured nature of the labor market means that it is treated implicitly as an undifferentiated entity, in the sense that persons with equal status scores or identical earnings in first job are considered to have equivalent prospects for advancement, subject only to the continued impact of the background variables and to "random" exogenous effects.

The notion of a career line is intimately associated with the view that the labor market is patterned-that determinable job sequences exist, common to the experiences of many workers, which can be understood in terms of institutional features of this market. The subjects of organization theory and industrial sociology describe the work settings within which the careers of individuals evolve. Career lines are shaped by the nature of industry structures (e.g., occupational distribution, mode of recruiting into upper status slots such as promotion from below vs. hiring from outside the firm) and by the institutional demography of the labor market (e.g., mix of industry types, which ones are expanding and which are contracting). The latter consideration is important because job trajectories often cross firm and industry boundaries instead of remaining entirely within them. A second objective in the study of work careers, then, is to understand the determinants of career-line features, especially how they are rooted in labor market organization.

Given the distribution of career lines in a locality, which trajectory a young worker will enter would appear to depend on his personal qualifications (intelligence, education), his predilection for a particular kind of work (molded by parental and peer influence), and the resources he can muster in competing for the entry-level position (e.g., material support from parents, sponsorship by influential others). With respect to many career lines it is reasonable to assume that background factors continue to influence status attainment and earnings, beyond facilitating access to the entry-level position. It is equally reasonable that in other career lines background factors have only a minor impact on rate of advancement, once entrance is secured (e.g., employees in seniority-graded bureaucracies; craftsmen in the construction trades). A third objective in the study of 
careers, therefore, is to ascertain the role of individual-level variablesespecially educational attainment-at different points in the career trajectory, carrying out this analysis for a variety of career lines. This endeavor would provide the study of socioeconomic achievement with more of an institutional context than presently characterizes this body of research.

Finally, as several authors have noted, career characteristics constitute an important determinant of an individual's life-style in social arenas besides the world of work. The most investigated career features are probably extent and direction of occupational mobility as these affect psychological dispositions, especially political preference (Lipset 1960, pp. 253-58) and prejudice (Hodge and Treiman 1966). Regarding other career features, Liebow (1967) stresses the concentration in ghetto neighborhoods of "dead-end jobs"-positions carrying little expectation of promotion or earnings growth-as a factor in the low work motivation of many residents. Also, Wilensky (1961), discussing associational participation, points to substantially higher rates of organizational membership among persons who have had "orderly" careers, in comparison with individuals who have experienced chaotic work histories. While there remains an issue of causality versus self-selection in many of these studies, the impact of work-career features on attitudes and behavior is a fourth topic warranting additional research. (The non-labor market consequences of career-line affiliation will not, however, be discussed further in this paper.)

Although some empirical results are presented, our principal concern here is to develop the career notion as a strategic link between structural features of the labor market and the socioeconomic attainments of individuals. Our use of data, therefore, is mainly illustrative, to demonstrate conceptual points, rather than analytic, to assess the contributions of particular factors. The organization of this paper proceeds according to the following themes: In the next section we review the treatment of careers in the occupational sociology literature and discuss some limitations with the traditional conceptualization. In Section II we enumerate the main features of career-line structures and present several illustrations. In Section III we outline two strategies for delineating career trajectories depending on the type of data available. In the concluding pages two crucial issues are sketched-the determinants of career-line structures, as they reside in labor market organization, and the relevance of the career concept for the study of socioeconomic attainment.

\section{TREATMENT OF CAREERS IN OCCUPATIONAL SOCIOLOGY}

The traditional literature on occupations and careers is dominated by case studies, frequently ethnographic accounts, of one or a very few 
occupations, firms, or industries. Accordingly, this literature abounds with such titles as Wall Street Lawyer (Smigel 1964), Organizational Scientists (Glaser 1964), Religion as an Occupation (Fichter 1961), Professional Soldier (Janowitz 1960), and Man on the Assembly Line (Walker and Guest 1952). In a related kind of inquiry, in contrast to providing a comprehensive overview of an occupation or a career line, researchers have focused on the performance of critical tasks peculiar to certain work situations: how policemen mediate squabbles (Wilson 1968, p. 21), how taxi drivers "size up" customers (Henslin 1968), and how failure is muted and made socially acceptable within large bureaucracies (Goldner 1965).

The key themes around which the comprehensive studies of individual occupations and career lines have been organized concern preparation for work, securing entrance into the occupation, remuneration and rewards, mobility, occupational associations, and phasing into retirement. The individual case studies employ, of course, concrete statements of these issues, tailored to the specific occupations investigated (see, e.g., Hall [1948] on stages in medical careers). A reading of these career accounts is revealing with respect to the variety of mechanisms which have been devised to accomplish the same essential tasks, such as socialization of new entrants, and with regard to commonalities among different sorts of occupations in the institutional forms employed.

Because of the great number of case studies executed on individual occupations and career lines, a more theoretical literature has evolved which has as its purpose collation of the ethnographic accounts via the construction of typologies. Typical of these endeavors are the classifications of Caplow (1954, p. 102) and Slocum (1966, pp. 45-75). Caplow groups occupations into four categories: independent fee-taking professionals, building craftsmen, semiskilled machine-tending factory workers, and small retail merchants. Slocum's categories place greater emphasis on institutional environments; he describes work arrangements on farms and in family-operated retail businesses, corporations, agencies of the federal government, educational organizations, and the military. Many other classification schemes exist, some being modest variants of the Census Bureau's major occupational groups (e.g., Ritzer 1972, p. 6; Taylor 1968, pp. 53-59).

The intent of these typologies is to reduce the variety of descriptions of detailed occupations and career lines to a small number of categories which can be scrutinized more efficiently. The categories devised by an author are subjected to investigation in terms of how key issues in the organization of work and career are resolved. A successful typology is one in which the fundamental issues are handled in a like manner or through similar organizational structures by the detailed occupations within a category, while differences in resolution apply to occupations in 
different categories. In short, the typology "accounts for" much of the total variation among detailed occupations and career lines in mechanisms employed to process key issues, in the sense that the alternative arrangements are identified and each is associated with a list of occupations and career lines.

The issues on which the construction of occupational categories tends to be centered are much the same ones as those raised in investigations of individual occupations; though, consistent with a study of properties of categories, the queries tend to be posed in a more general manner and the results of the analyses maintain this quality. Caplow (1954, pp. 102-20), for example, organizes his discussion of occupational types around the following themes: manner of recruitment, returns to seniority, evaluation of merit, control over occupational behavior and extraoccupational behavior, occupational culture, formation of occupational attitudes and occupational stereotypes, and rate of growth or decline in employment. Ritzer (1972, p. 11) considers the same essential issues but arranges his discussion of the categories around institutional conflicts and problems, as an additional frame of reference.

Now, even though researchers in occupational sociology use the term "career" when discussing work experience and occupational stages, they tend to conceptualize this notion in a way that detracts from the delineation of actual career lines and the study of their determinants. While we use the term descriptively, to denote a person's work history, the common usage is prescriptive. This is apparent from comments by various authors. Slocum (1966, p. 5), for example, defines career as "an orderly sequence of development extending over a period of years and involving progressively more responsible roles within an occupation." With reference to work histories in industrial firms, he adds, "The theoretical model involves entry into a position that requires the performance of occupational duties at the lowest rung ... followed by higher-level positions within an organization." Such a characterization leaves little room for work histories which do not exhibit an orderly pattern. Moreover, it detracts from the view of career lines as empirical regularities in the labor market, to be determined through the examination of data, and from the perspective that variations in career-line features are matters to be explained. Ritzer (1972, p. 43), who follows Slocum in adopting an ideal-type perspective, is quite explicit on this point. He states that "the [career definitions] tell us very little about actual career patterns."

A second difficulty with career accounts in the occupational sociology literature stems from distinct biases in the types of careers that are discussed. Many of the ethnographic materials upon which the accounts are based derive from case studies of individual occupations, firms, or industries. The career lines delineated from these observations are almost 
exclusively trajectories within institutional structures. We have descriptions of typical careers of policemen, construction craftsmen, teachers, and assembly-line workers ${ }^{3}$ but only the most rudimentary information about career lines that transverse institutional boundaries or about the related phenomenon of career change in mid-life. We know little about the frequency of cross-institutional career paths or about the sorts of jobs that form them. These matters presumably translate into questions concerning which skills are transferable and to what extent workers in different industries are constrained by investments in seniority and pension rights. Investigations of career change in mid-life would involve the additional considerations of promotion blockage in a career line and deterioration in work satisfaction with age. Such topics have received only passing mention by researchers (see Sofer [1970], though, for an exception).

What emerges from this brief review is an idealized description of occupational careers, which may be quite useful in the study of stratification arrangements, organizations, and occupations-where "career" is an adjunct consideration, one of several concepts introduced to elucidate the main subject. However, for the purpose of delineating empirical career lines and understanding their determinants in industry structures and labor market composition, the existing accounts are inadequate. The prescriptive formulation, characteristic of the literature, is not well suited to investigating the properties of career trajectories; moreover, the categories used in the occupational sociology literature are not the appropriate ones for summarizing the variety of career-line types or elucidating their significant features. ${ }^{4}$

Job-change patterns.-It is not the case that the empirical description of careers has been entirely neglected, though the number of such studies is small. A partial step toward career-line delineation was taken in the early 1950 s by several researchers who sought to analyze the character of job shifts. Lipset and Bendix $(1952 a, 1952 b)$ examined the frequency of three kinds of shifts - employer change, occupational change, and community change-relating each to other variables. For our purposes, their most significant findings concern variations in job-change behavior by occupation and age. They report that occupational change is least common among professionals and skilled workers (careers for them approximate

3 These accounts commonly review career stages from the perspective of the employing organization: entrance into the firm or agency (e.g., factory, police department), movement among its statuses, departure from it-see Stewman (1975) for a wellexecuted example. What an individual's work history was prior to entrance and what it is subsequent to departure are not addressed.

4 Another drawback to the occupational classifications is that they usually lack industry detail. It is well known (e.g., Blauner 1964; Woodward 1965), though, that industries differ in regard to promotion prospects and separation rates, matters of relevance to career structure. Additional comments on industry effects are made in Section IV. 
the traditional descriptions in the occupational sociology literature) and that the frequency of all types of shift decreases with age. Reynolds (1951, pp. 19-36) enumerated many of the same results but added several observations about industries. In particular, he introduced the notion of "neighboring industries," among which the flow of labor is intense. He noted, for example, that the trade and service sectors show a marked interchange of labor with each other, while clothing manufacturing occupies a relatively isolated position, exchanging few workers with other industries. His observations are pertinent to career-line description as they relate the frequency of cross-industry trajectories to career origins.

The most comprehensive investigation of job-shift behavior is reported in Gladys Palmer's seminal volume, Labor Mobility in Six Cities (1954). For the decade 1940-49, she described job-change patterns for approximately 5,000 males as well as for a smaller female sample. Job shifts are divided into several mutually exclusive categories: employer only; employer and occupation; employer and industry; employer, occupation, and industry; and other shift type. Her findings are consistent with the preceding studies, though she introduced several refinements. With individuals categorized according to their 1949 occupations, a higher frequency of employer-only shifts, relative to other shift types, was detected among professional workers and craftsmen. With respect to industry affiliation in 1949, she noted a corresponding tendency to employer-only shifts among construction workers. Additionally, she reported that a simultaneous change of employer, occupation, and industry-presumably a new career beginning - declines with age, relative to other shift patterns; while the frequency of employer-only moves, as a percentage of all job changes, increases with age.

In the past two decades the analysis of job-shift behavior has been subordinated in stratification and mobility research to the study of status and earnings change, as these matters are formulated in socioeconomicattainment models; that is, without regard to the pattern of movement. However, several recent investigations have sought to capture more of the complexity in job-change behavior than is conveyed by the two measures of career returns. Spilerman and Miller (1973) examine how the character of job shifts (quality of position left, quality of position entered) would be altered for low-income workers under a negative-income-tax program. Sørensen (1975) distinguishes between voluntary and involuntary job changes, and analyzes black-white differences in labor market opportunity in terms of this consideration. Also, Parnes and Nestel (1974), in a preliminary report on the middle-aged male sample from the National Longitudinal Survey of Labor Market Experience, investigate earnings growth among voluntary job changers, involuntary job changers, and 
nonchangers. All these recent studies employ less elaborate job-shift categories than the ones used by Palmer (1954), yet they represent a clear tendency to return to more detailed descriptions of job-change patterns than has been common in socioeconomic-achievement models.

The preceding studies were characterized as a partial step toward career-line descriptions because the analyses refer to transitions between a pair of jobs, not to complete work histories. There are, however, a few tentative beginnings toward the more ambitious objective of delineating career lines and identifying their features. Form and Miller (1949) display job histories for 276 persons. The individual career trajectories are grouped according to the major occupational category of last job in the sequence (current position). In discussing the trajectories, Form and Miller emphasize the career features "amount of vertical mobility" and "amount of time spent in each career stage" (initial work period, trial period, stable work period). They show that distinct differences in job histories and mobility patterns pertain to persons currently in each occupational category. Wilensky (1961) reports on the work experiences of 678 men from middle-class backgrounds. In addition to the career dimensions "direction" and "amount" of job change, he gives special attention to "degree of orderliness of a work history." By this phrase he means how well it conforms to the notion of "one job [leading] to another, related in function and higher in status" (p. 522). Wilensky concludes that only one-third of his middle-class sample have work histories which can be described as orderly.

A final study deserving note is a theoretical contribution by Thompson, Avery, and Carlson (1968). The authors use the term "career" in a neutral sense, much as we do, to denote "any unfolding sequence of jobs" (p. 7). They distinguish between an "orderly career" (identical with Wilensky's usage of the term "career") $)^{5}$ and a "disrupted career," one in which a change of occupation has occurred. ${ }^{6}$ In conjunction with these career types they introduce career-line features which have not received attention from other researchers and which are well attuned to the evolutionary nature of careers: the shape of earnings and status trajectories (early ceiling, late ceiling) and the notion that a career beginning may lead to branches-multiple career-line options-several of which may be

5 Wilensky (p. 523) associates the term "career" with a life plan. He counterposes "disorderly work history" to "career" when discussing job sequences that do not conform to the notion of one job leading to another with greater rewards. Identification of the career concept with a progression of successively higher ranked positions is common in the occupational sociology literature (e.g., Taylor 1968, p. 266; Sofer 1970, p. 65).

6 The notion of "disrupted career," as specified in Thompson et al. (1968, p. 21), is unusually restrictive. They would consider the shift of a nurse or a teacher into administration as an instance of career disruption. In contrast, we view such shifts as part of orderly career progressions. 
orderly, though with different long-term consequences for the incumbents. We return to these considerations in the next section.

To summarize, our assessment of the occupational sociology literature in regard to the light it sheds upon work careers is that this body of research has led to an incomplete characterization of the variety of career lines present in the labor market. The literature consists more of ideal-type specifications than descriptions of empirical regularities, and the emphasis is on orderly lines of progression. This literature is strongest in relation to career lines which lie entirely within one of the institutional categories recognized in occupational sociology (e.g., profession, craft occupation, industrial firm), but it is less adequate in dealing with complex trajectories. Related writings on job-shift patterns and on careers per se provide important insights into career-line structures and the determinants of their features, yet no systematic attempt to actually describe the variety of trajectories in the labor market on the basis of empirical data has been undertaken.

\section{FEATURES OF CAREER LINES}

In this section we outline several properties of career lines, our purpose being to convey some of the complexities of these structures preliminary to considering methods for delineating detailed career trajectories and assessing their role in the socioeconomic-attainment process. Two themes are interwoven: we describe career lines as relatively stable labor market structures through which workers "flow"; at the same time we indicate how certain attributes of individuals - in particular, age-influence the paths that will be available to them. Since the underlying objective of this paper is to argue the importance of career lines for understanding socioeconomic achievement-a topic which is addressed in the concluding section-we devote special attention here to life-cycle trajectories in career rewards.

Our point of departure from the occupational sociology literature stems from our view of the labor market as a system, in the sense that work organizations are overlaid with multiple career trajectories, which may transverse those units and which are themselves linked via transition opportunities from one career line to certain others. In some cases a career line consists of a sequence of positions within a single firm through which a worker must progress in a rigid manner: entry occurs at the bottom of the job ladder, and promotion is through well-specified grades (e.g., police and fire departments). Other trajectories are less well delineated by institutional rules and may contain several entry-level positions as well as multiple departure points to alternative career lines. (For instance, an electronics technician may learn his trade in school or be 
promoted to the job from a craft occupation [electrician]. From this position he can move upward to an engineering or a managerial slot or downward to a craftsman job. Lateral moves across industries are also common: electrical machinery, computers, airplane manufacturing, and hospitals all employ significant numbers of electronics technicians.)

In order to examine the labor market as a system of interconnected career lines, it is necessary to specify the trajectories empirically rather than employ a priori notions as to which specific jobs should be linked together. To proceed otherwise would not permit use of a high level of disaggregation in the definition of a job (such as the six-digit occupation/ industry code of the U.S. Census) and would entail gross simplifications in the descriptions of career structures. For the present discussion we define a career line as a collection of jobs in which there is a high probability of movement from one position to another on the list; in short, it is a sequence of jobs common to a portion of individuals in the labor force. This primitive definition will be amended as we entertain certain complexities of careers.

Ports of entry. ${ }^{7}$ - A career line begins with an initial position. We define an entry portal as a job in the career line held by a significant proportion of persons without prior employment in another position in the trajectory. Some career lines have a single entry portal. To become a police lieutenant, for instance, one must have been previously a patrolman and a sergeant, usually in the same community. Not every patrolman becomes a lieutenant or sergeant; yet, in order to discuss how jobs are linked, it is convenient to specify the career line as originating with the entry-level position and continuing to the highest rank which draws a substantial proportion of its personnel from the lower capacities (e.g., police captain). To convey the frequency of mobility, transition probabilities can be associated with each job, or appended to each year in a grade, to indicate the likelihood of promotion or demotion as a function of number of years of prior service (see Stewman 1975).

With respect to a policeman's career line, the entry-level position is unique. Other trajectories, though, have multiple entry portals. For example, one can become a skilled craftsman in a manufacturing firm by being promoted from an assembly-line job, by completing an apprenticeship program, or by studying a vocational curriculum in high school. Indeed, many career lines permit stages to be skipped, replaced by educational credentials or by work experience outside the particular trajectory. As a consequence, individuals who enter the career line through different portals will frequently be dissimilar in age and education-factors likely

\footnotetext{
7 This term is taken from Kerr (1954, p. 101). His concern, though, was not with career-line structure but with labor market organization, a subject which we address in Section IV.
} 
to have an impact on their subsequent rates of advancement and on career returns.

One difficulty with our specification of a career line arises from the presence of branches. Our definition refers to a sequence of positions (e.g., assembly-line worker $\rightarrow$ foreman $\rightarrow$ manager). Yet, while this progression may denote an empirical regularity, in the sense that a majority of managers in a particular industry have traversed the path, it nonetheless might be typical of the histories of few individuals who begin work on the assembly line. Indeed, any career-line path-that is, an ordered sequence of jobs-in which the entry-level position has numerous branches may be depicting the mobility prospects of few workers in the initial position. In order to address the various kinds of issues which arise in the study of careers, it is therefore useful to employ two complementary perspectives: descriptions of career-line fragments (paths) associated with critical positions in the labor market (e.g., manager in industry $\mathrm{X}$ ) and specifications of the expected progress of workers who enter the career line via different portals.

We illustrate the two perspectives in figure 1 . In panel $A$, the paths associated with a hypothetical managerial position are depicted (solid lines). The figure shows that entrance may be directly into this position from outside the trajectory (dashed arrow to "manager") or through promotion from a lower-ranked status in the career line (solid arrows from "foreman"). In this representation, a branch to a new position is defined when, say $12 \%$ of a cohort in the origin status have made the transition. The incline is begun when, say, $3 \%$ have made the shift and terminated when, say, $9 \%$ of workers have made the move. ${ }^{8}$ (The same transition may be repeated at a later time if the branching criterion is again satisfied.) Also, because individuals who enter via different portals may be dissimilar in background characteristics and in expected rate of advancement, the converging paths are kept distinct. One might, of course, choose to ignore prior work history, in which case the parallel lines pertaining to a single position would be merged.

In panel $B$ we illustrate the complete collection of career-line paths that emerge from a common entry-level position (career tree). ${ }^{9}$ The fragments associated with the managerial position are drawn in a heavy black line to offset them from the remainder of the tree and facilitate comparisons between the two representations. Also, the career-line paths which link the managerial position to other entry portals (light lines in

8 Consequently, the slope of an incline indexes the age specificity of the transition in that a steep rise is associated with a narrow age window. (The measure of dispersion suggested in the text is the interquartile range.)

9 Although the term "career tree" provides a more apt description of how jobs are linked together than "career line," the latter phrase is common usage, and where there is no confusion we will employ it as a generic term for job-sequence structure. 

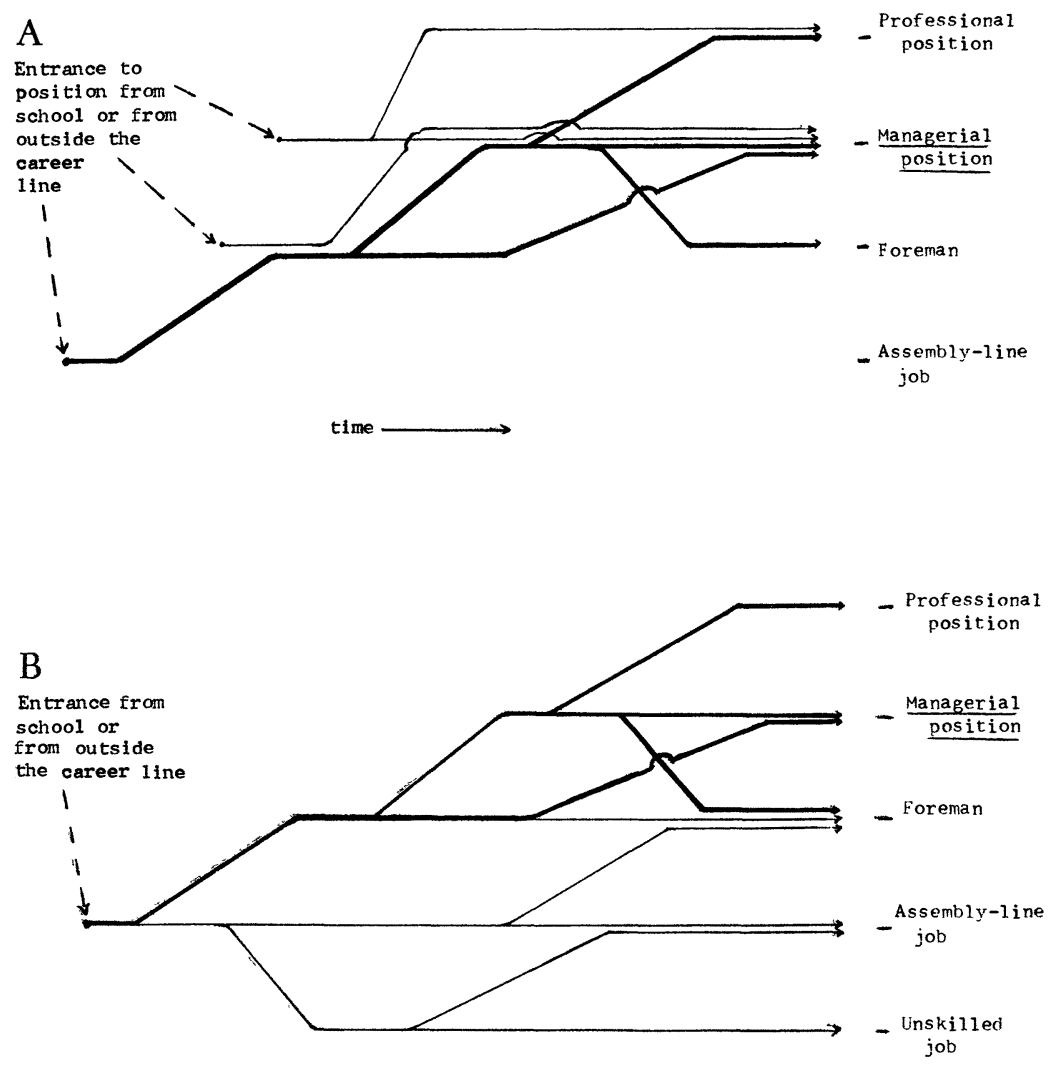

time

FIG. 1.-Career-line paths associated with a key position and career tree which emerges from an entry portal (hypothetical data).

$A$. Paths associated with the position "manager in industry $\mathrm{X}$."

$B$. Career tree which emerges from an entry portal.

There is no substantive meaning to the ordinal value in either $A$ or $B$; the intention at this point is only to distinguish among the career-line paths. The starting points of the different portals in $A$ are located in time according to the (hypothetical) average age of entrants. Since individuals who enter a position via different portals or follow different paths may be dissimilar in their characteristics and in rates of advancement, converging paths are kept distinct. See text for statement of the branching criterion.

panel $A$ ) are now deleted because the emphasis here is on intake through the single portal "assembly-line job." In the interests of simplicity the paths are few in number and are not assigned frequency values. Yet it should be evident that the most common trajectories might not include the managerial position.

Each approach to career-line delineation has its utility, the choice depending on the substantive issues under investigation. When one is 
interested in ascertaining recruitment patterns into key positions in the economy and in the evolution of careers from those positions, the former approach is called for. It is not, incidentally, different in spirit from the career descriptions which comprise much of the occupational sociology literature, though our emphasis is more heavily on capturing the full range of complexity in worker movement. Research questions consistent with this formulation concern the number of inlets to a key position, the personal characteristics of incomers through each, and the subsequent career progress associated with entrance from a particular path.

In comparison, the investigation of career-line paths which emerge from a common entry portal (career tree) is relevant to comprehending the socioeconomic achievements of individuals, since the expected lifecycle returns in earnings and status of a beginning worker are functions of the returns from the component paths, each weighted by its probability of being followed. This approach to career-line analysis mirrors the contingencies that will face a person as his career unfolds; that is, it depicts his job-change options (as well as the shifts that may be imposed upon him). Complex branch choices, incidentally, are also common within broadly defined occupational strata. A young manager in an industrial firm, for example, must orchestrate his tour of jobs with care if he is to avoid mobility blockage (Sofer 1970, pp. 234-40). To maximize promotion prospects, it is advisable to be identified with a large product division of the company and with an influential functional unit (e.g., marketing, production), and yet accumulate service in several of these organizational entities so that when a senior position in central administration opens he is not looked upon as a "local."

Branches and career-line change.-With respect to promotion prospects, a worker's age is a crucial consideration. Just as age is related to the portal by which a career line is entered, it continues to be consequential as a determinant of the branch options that will be available. Stated more succinctly, where a job leads is very much a function of age. To be a foreman when one is young, for instance, means that one is well positioned for promotion to the managerial ranks, while to be in the same job a few years later may define the individual as too old for further advancement.

Some issues which require consideration with respect to career-line branches concern (1) the breadth of the "tree" associated with a portalthat is, how many distinct paths emerge from an entry-level position; (2) the age at which each branch option opens and the additional requirements (e.g., educational credentials) necessary for admission; and (3) the age at which a branch option closes, in the sense that the proper time to enter, if one intends to pursue upward mobility, has passed. These issues merely outline the terrain which should be examined in regard to 
career-line branches. A related topic involves distinguishing the long-term from short-term prognosis in following a branch option; for instance, some promotions lead to "dead-end" career-line paths, in the sense that few higher-level positions are on the branch. ${ }^{10}$

In addition to branch selection within a career line, it is not uncommon for individuals to terminate one career and enter a new trajectory during their work lives. ${ }^{11}$ We can specify in general terms "push," "retention," and "pull" factors that would be involved in career-change decisions. By push factors we mean the considerations which make continuing in a line of work unattractive: dissatisfaction with earnings or status, physical difficulty or tedium of the task, and little expectation for improvement in these matters. Concepts such as task alienation (Blauner 1964) and promotion blockage (Sofer 1970) are frequently invoked in explanations of career change in mid-life.

Retention factors speak to attachments to the career line which keep a worker in harness despite a high level of dissatisfaction. Foremost are considerations of seniority with the firm, pension rights, and lack of transferability of work skills to other industries. As one might expect, the cost of changing careers increases with age, so it is not surprising that simultaneous shifts of industry and occupation-which often signify a career-line switch-decline with age (Palmer 1954, p. 76). By pull factors we refer to the countervailing options open to an individual in other career lines. In some instances (e.g., professional athlete) they result from the transferability of reputation, if not of specific career-line skills. More commonly, pull factors relate to the industrial composition of a community. The presence of a variety of industries should make for greater success in locating second careers than concentration of the labor force in a few industrial sectors. Small towns, especially one-industry towns, would be particularly difficult settings within which to effect career changes.

From an analytic perspective, the investigation of mid-life career change patterns should consider $(a)$ which primary career lines are especially vulnerable to departures, in the sense that this is a frequent phenomenon, and what are the reasons for the departures; $(b)$ which sorts of jobs can be entered late in life and can thereby serve as entry portals to second careers (some evident examples are retail clerk, bank guard, and insurance salesman); and $(c)$ what linkages exist between primary career lines and

10 Demographic considerations may also define a job as "dead-end." If one's immediate supervisors are all young, this will mean a slower rate of advancement than if some were approaching retirement age. In a relatively new industry which has stopped expanding (e.g., astronautics), this kind of promotion blockage can be quite pervasive. 11 This sort of shift is easily discernible for workers who have had an orderly career, in which there is continuity in job progression, up to their points of departure. For individuals with chaotic work histories, the notion of career-line change is ill defined, unless one means by this a shift in type of career (e.g., from chaotic to orderly). 
jobs not formally components of them but which recruit from the trajectories-for example, bank guards are drawn disproportionately from among older policemen. We return to these matters later in this section when we discuss the related notion of vulnerability of individuals in different career lines to the effects of aging.

Career returns.- This array of considerations refers to the rewards from affiliation with a particular career line. In gross terms, the rewards consist of earnings, status, and work satisfaction; the last of these having several facets, relating to different job dimensions. The life-cycle perspective intimated by the notion of career returns suggests that we examine the trajectory of each reward component over an individual's work life.

For most career lines there is a characteristic shape to each of these trajectories. The shape of earnings tends to be concave downward, consisting of a rise early in one's work life, a plateau through the middle years, and a slight decline toward the end of the work career. Status trajectories have the same basic form, though they tend to be flatter than the earnings curves. We know least about how work satisfaction changes over the life cycle. Wilensky (1960, p. 549) describes a satisfaction trajectory which is not unlike the preceding accounts of earnings and status: "a low period in the twenties, a climb to a peak in the middle years, a slight drop-off and then a final sag in the sixties." Now, Wilensky does not discuss the trajectories of components of work satisfaction, though it is evident from his comments that he is referring principally to satisfaction with earnings and job status. In a more detailed investigation, Palmer (1957, p. 21 ) reports that emphasis on achievement in work is a typical response of young individuals, while emphasis on economic security is associated with older workers.

Although the study of life-cycle trajectories in career returns is a largely undeveloped research area, one aspect which has received attention concerns earnings curves. The basic shape of these curves-estimated from cross-sectional data-is well known, and some work has also been done on ascertaining how the form of life-cycle earnings varies with level of educational attainment (Becker 1964; Hanoch 1967; Mincer 1974) and with occupational affiliation (David 1969; Stolzenberg 1975). The main findings are to the effect that well-educated individuals experience a lengthy interval of earnings increase in youth and an earnings decline at a late age, in comparison with poorly educated workers for whom the earnings peak and the decline onset occur at a younger age. Yet only in a few instances are the occupational curves career-line trajectories. In particular, with the exception of the professions and some craft jobs, detailed occupations tend to be components in a job sequence and have concentrated age distributions. Moreover, even when the age distribution 
is relatively broad, this may not mean that the occupation is a lifetime affiliation but, rather, that individuals of different ages can sojourn in it. ${ }^{12}$

We illustrate these considerations in figures 2-4 for a few career lines, chosen to display a variety of earnings-trajectory structures. In each figure the upper panel reports earnings at five-year intervals for workers in the noted job (six-digit Census occupation/industry code) in both 1965 and 1970. The figures were calculated from the 1970 Census 1/100 sample tape using pooled data from 12 SMSAs, and represent an estimate of the shape of earnings for an individual who remains in the job ${ }^{\mathbf{1 3}}$ throughout his work life. In the lower panels several curves are displayed; each represents an estimate of the earnings trajectory for an individual who was in the position of record before the age interval on the curve but has departed by that period. These curves have been plotted net of stayer earnings, which are represented by the horizontal axis. ${ }^{14}$ Therefore, to the extent that a curve lies above the axis, leaving the job before the specified age interval proves, on average, to be financially advantageous; to the extent that a trajectory lies below the axis, the expected life-cycle

12 As these comments indicate, it would be a worthwhile endeavor to examine the age structure of occupation/industry positions in the economy. Cursory inspection of occupation data from the 1970 Census 1/100 sample tape reveals several broad patterns: Some jobs (e.g., telephone lineman, file clerk) have age distributions skewed toward the young end and are clearly entrance positions into career lines. Others (e.g., foreman, manager) contain an overrepresentation of middle-aged workers but few young individuals. These positions do not, however, have a concentration of persons in their sixties, as the jobs are principally in organizations with retirement rules. Old persons in the labor force are concentrated in pursuits which require little exertion, can be performed part time, or permit the individual to control his rate of work. Examples are janitor, real estate salesman, and dentist. Industry effects are also present, superimposed upon these occupational patterns: apparel manufacturing (in the 12 metropolitan centers we have examined) has an overrepresentation of old workers; computer-programming services have a young age distribution. One evident cause of industry effects is employment growth rate; young age structures are associated with expanding sectors, while declining industries tend to have older workers, at least when the employment decline is not a consequence of the introduction of new technologies. Discussions of occupation-age structures and their special relevance to vocational counseling may be found in Super (1957) and Smith (1974).

13 Unless stated otherwise, we shall mean by "job" an occupation/industry affiliation. The 1970 Census does not contain employer-change information; hence we are unable to distinguish truly stable individuals from "stayers" in an occupation/industry position who have switched employers. The significance of this data gap for our understanding of career-line structure differs by origin job. For mail carriers, within-industry employer shifts are virtually nonexistent, while for construction craftsmen they constitute an important dimension of career development.

14 To understand the contours in panel $B$, consider the following example. The top curve in fig. 2, labeled $23-27$, reaches the point +3 at the age range ( $x$-axis) 28-32. This says that, for individuals who left the occupation/industry position by the age interval $23-27$ but had been in the job five years earlier, their expected earnings in the age range $28-32$ are $\$ 3,000$ greater than for mail carriers (stayers) in the age range. For additional details, see notes to table 2 . 
A
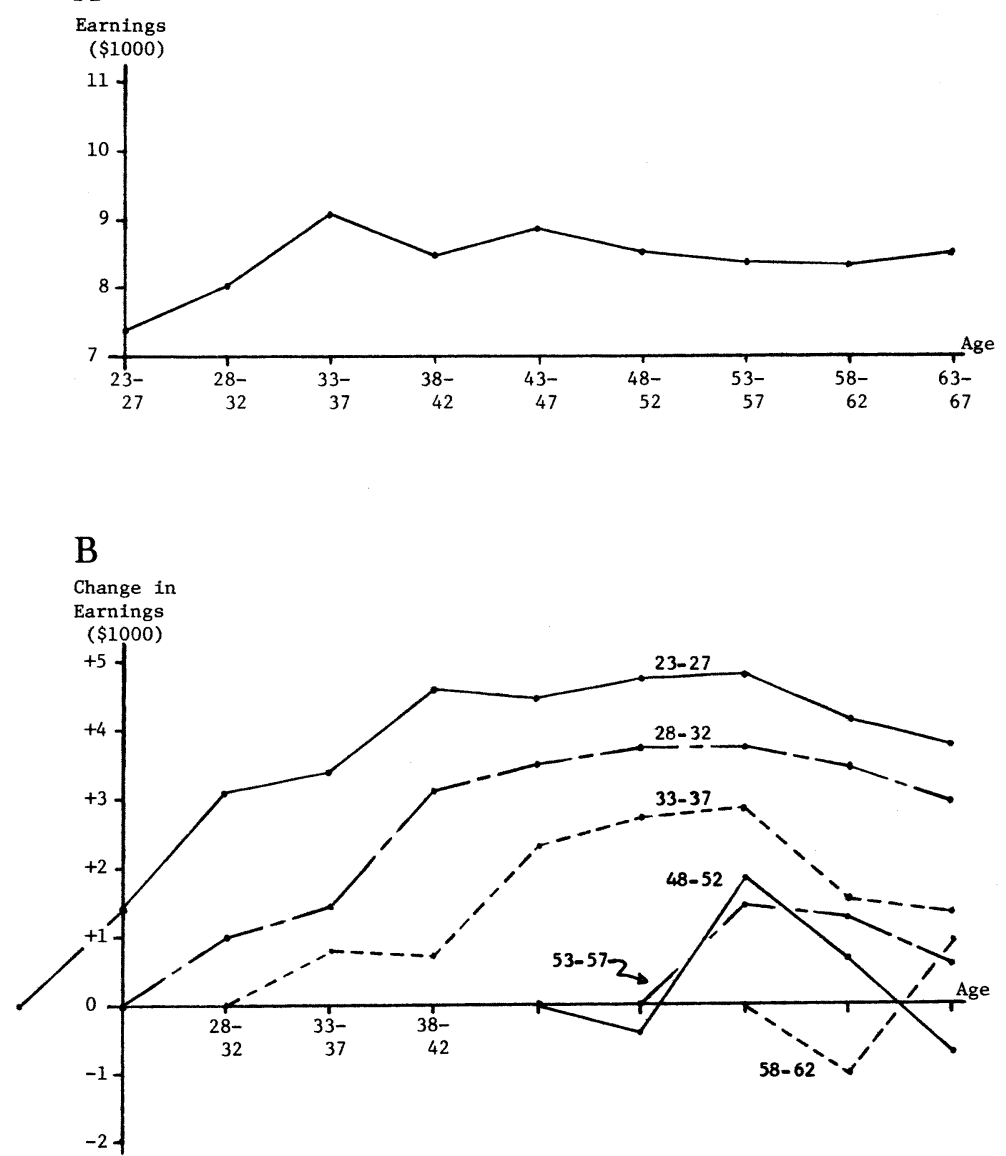

FIG. 2.-Life-cycle earnings trajectories for mail carriers. "Mail carriers" refers to the 1970 Census occupation/industry codes 331/907. Earnings data are from the 1970 Census 1/100 tape and pertain to the male population in 12 northern SMSAs. Individuals not employed in 1965 or who worked fewer than 40 weeks in 1970 were omitted. The latter exclusion was made so that the earnings figures would be based on full-time workers.

$A$. Expected earnings of stayers in the occupation/industry position. "Stayers" refers to individuals who remain in the same occupation/industry position throughout their lifetimes. Estimates of stayer earnings are based on 1970 earnings of individuals who did not change occupation/industry affiliations between 1965 and 1970. For details on (approximate) number of observations in the age categories, see panel $A$ of table 1 .

$B$. Expected earnings of movers from the occupation/industry position, by age at move. "Movers" refers to individuals who have changed occupation or industry affiliations by the age interval marked on a curve, but had been in the origin position five years earlier. The earnings figures for movers are net of stayer earnings for the same age category. Each trajectory in panel $B$ therefore describes the earnings differential between movers and stayers at various ages. For example, the top curve, labeled $23-27$, reaches the point +3 at the age range ( $x$-axis) 28-32. This says that, for individuals who left the occupation/industry position before the age interval 23-27, expected earnings in the age range 28-32 are $\$ 3,000$ greater than for mail carriers (stayers) in the age range. Trajectories for movers were constructed using the simulation procedure described in Section III. In brief, the earnings curves for movers were estimated from the transition experiences of different population cohorts during the five-year interval 1965-70. Curves for middle-aged departers are omitted to enhance readability. The $x$-axis has same legend as $x$-axis in panel $A$. 


\section{American Journal of Sociology}

A
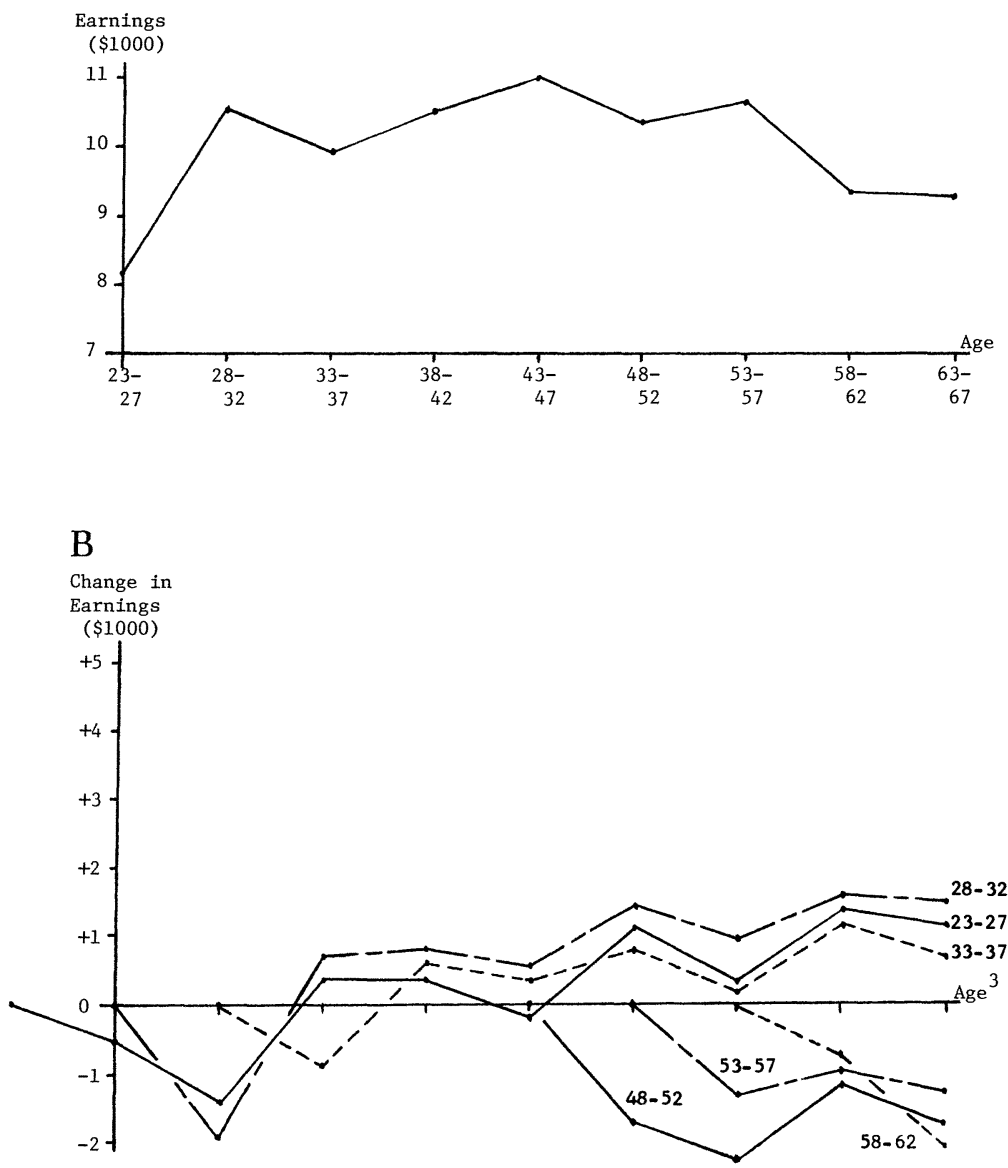

FIG. 3.-Life-cycle earnings trajectories for truck drivers in trucking services. "Truck drivers" refers to the 1970 Census occupation/industry codes 715/417. A. Expected earnings of stayers in the occupation/industry position. $B$. Expected earnings of movers from the occupation/industry position, by age at move. See legend to fig. 2 .

return from departing by that age is deleterious, in comparison with stayer earnings.

Figures 2-4 are revealing on a number of points. With respect to the "stayer" curves (panel $A$ ), while the age-earnings contours of truck drivers and construction carpenters conform to the inverted-U pattern associated with earnings curves, ${ }^{15}$ the trajectory for letter carriers is flat.

15 The reader who is familiar with age-earnings profiles for education levels might be surprised by the flatness of the three "stayer" contours. As the "mover" curves in panel $B$ suggest, much of the curvature in age-earnings profiles for education groups derives from the sequencing of individuals among jobs with different wage rates, rather than from earnings growth within a position. 
A
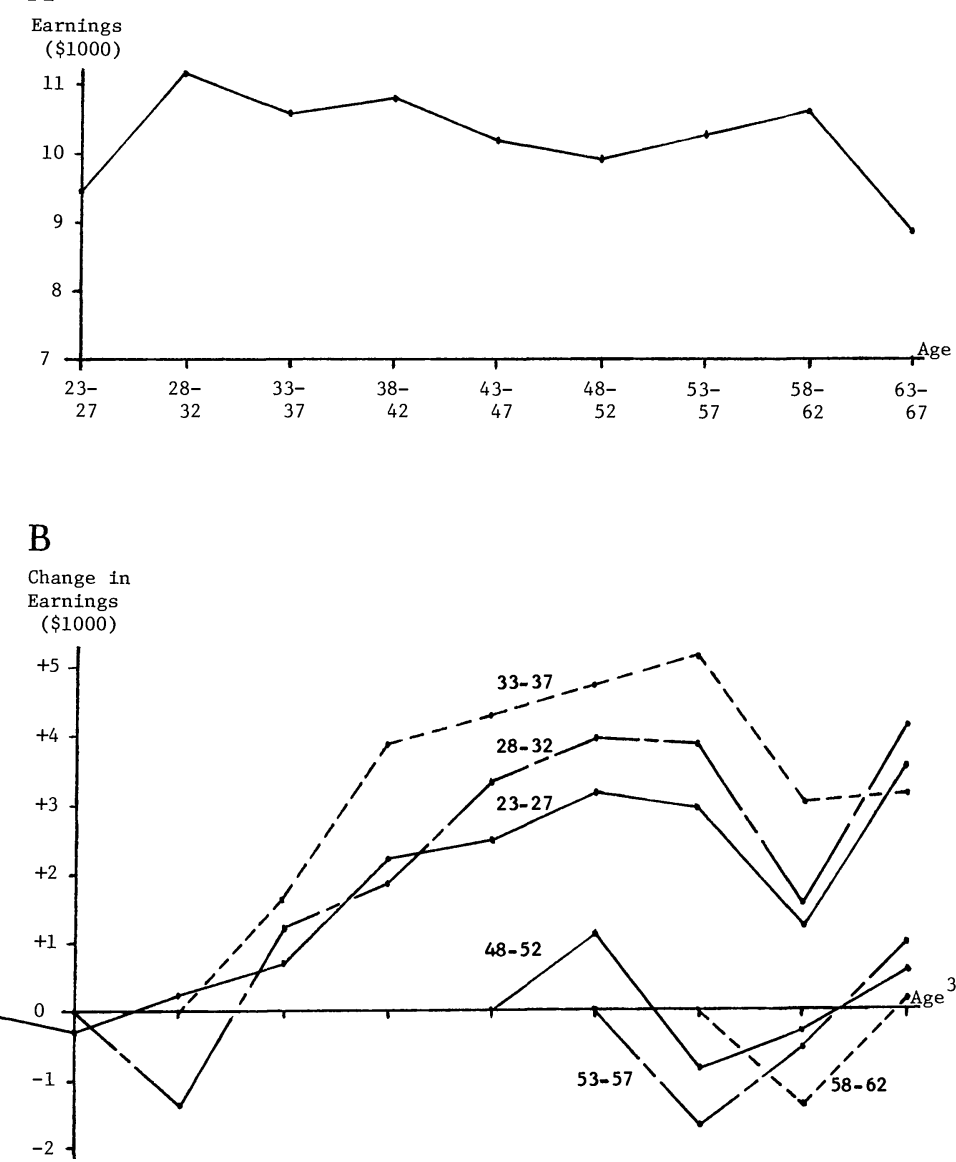

FIG. 4.- Life-cycle earnings trajectories for construction carpenters. "Construction carpenters" refers to the 1970 Census occupation/industry codes 415/67. A. Expected earnings of stayers in the occupation/industry position. $B$. Expected earnings of movers from the occupation/industry position, by age at move. See legend to fig. 2 .

This anomaly is probably due to a salary schedule for post-office workers which makes little allowance for years in grade, an arrangement which is also found in other civil service bureaucracies (e.g., police and fire departments). Comparing the three stayer curves it is apparent that, to the extent individuals make careers out of single occupations, their prospects for earnings growth and the overall shape of their earnings contour will depend very much on the chosen pursuit.

Yet this is not the most common sort of career pattern, and the curves in the lower panels are more interesting for our purposes as they mirror the career contingencies of individuals in a more realistic fashion. What 
is revealed by the earnings trajectories of departers at different ages from the six-digit occupation/industry codes is that there is an appropriate time at which to leave a job and a time to avoid leaving, if one's objective is to maximize future earnings. It is also the case that the consequences of departing from a job at a given age differ substantially by origin position. In particular, mail carriers (fig. 2) would be well advised to leave early, as earnings prospects are most propitious for young departers, presumably because they are physically able and because experience in letter carrying is not a sought-after skill. By age 50, the earnings prognosis for new departers has deteriorated to the point where little benefit is to be had from changing jobs.

Truck drivers (fig. 3), in comparison, exhibit a more involved ageearnings structure. In the initial years following a departure, their earnings tend to be depressed, relative to the remuneration of stayers. For young workers, however, the decrease is temporary; and, within 5-10 years of leaving, it is replaced by a modest earnings gain, relative to stayers of the same age. Unlike mail carriers, the precise age of departure appears to have little impact on subsequent earnings, at least for the three youngest groups. For older job changers no improvement is noted, possibly because they do not remain in the labor force for a sufficient period to overcome the initial earnings decline, though their advanced age must impose an additional handicap as well. With respect to construction carpenters (fig. 4), there is yet a different earnings pattern: over the initial age groups the expected earnings of departers increase with age, to some extent because the skills accumulated in this pursuit would be attractive to employers in other industries such as furniture manufacturing. Older workers, again, show little earnings gain from changing occupation or industry affiliations.

These curves illustrate the considerable disparity between the trajectories of stayers in an occupation/industry code and movers from the job. They also serve to emphasize the extent to which an individual's earnings prospects are contingent upon age of departure-presumably because the branch options available to him change with age-and to underscore the dependence of this entire earnings structure on the specific career line. To pursue these matters further one should examine the characteristics of job departers of different ages and the companion issue concerning type of transition made. We comment here on the latter topic, which is the more structural consideration, and discuss it only briefly to illustrate the most obvious patterns.

The 1970 Census lacks information for studying employer changes or distinguishing voluntary from involuntary job departures. One can, however, investigate shifts in occupation or industry affiliations during the interval 1965-70; therefore this discussion is restricted to life-cycle 
patterns in these variables. Specifically, we consider four types of shiftsame occupation and industry in 1970 as in 1965; same occupation, different industry; different occupation, same industry; and a change in both affiliations during the five-year interval. The last of the shift types provides an estimate of the rate of career-line changing, in that abrogating links to both occupation and industry frequently means relinquishing one's investment in the skills and seniority benefits associated with a work career. In contrast, shifts in which occupation or industry is maintained are more apt to reflect sequencing within an orderly job progression.

In panel $A$ of tables 1-3 the distribution of occupation/industry shift types is reported by age category for mail carriers, truck drivers, and construction carpenters. One prevalent pattern concerns the tendency for a simultaneous change of occupation and industry to be characteristic of the very young, who are least encumbered by sizable investments in career-line skills and pension programs. In the oldest age group there is also an increase in the proportion of occupation and industry changes. Postal workers can retire and receive pensions after 30 years of service; our data suggest that many use this opportunity to begin second careers. For truck drivers and construction carpenters there is a tendency to transfer into less physically demanding lines of activity in the later stages of work life. Another evident pattern in type of job shift is the accom-

TABLE 1

ChaNges in OCCUPATION/INDUSTRY AFFiLiations* DURING 1965-70, BY AGE, FOR MAIL CARRIERS $\dagger$

\begin{tabular}{|c|c|c|c|c|c|c|}
\hline \multirow[b]{2}{*}{ ShIFt Type } & \multicolumn{5}{|c|}{ AGE IN 1970} & \multirow{2}{*}{$\begin{array}{c}\text { Ali } \\
\text { PERSONS }\end{array}$} \\
\hline & $21-30$ & $31-40$ & $41-50$ & $51-60$ & $\geq 61$ & \\
\hline & \multicolumn{6}{|c|}{ A. Percentage Distribution of Shift Types, by Age $\ddagger$} \\
\hline Same occ/ind. & 58.3 & 73.3 & 86.8 & 83.9 & 60.0 & 79.0 \\
\hline Same occ/different ind. & 0 & .0 & .0 & 0 & .0 & .0 \\
\hline Different occ/same ind. & 6.7 & 7.3 & 6.8 & 4.4 & 6.7 & 6.4 \\
\hline Different occ/different ind...... & 35.0 & 19.4 & 6.4 & 11.7 & 33.3 & 14.6 \\
\hline \multirow{3}{*}{$\begin{array}{r}\text { Total. } \ldots \ldots \ldots \ldots \ldots \ldots \ldots \ldots \\
N \text { observations } \ldots \ldots \ldots \ldots \ldots \ldots\end{array}$} & 100.0 & 100.0 & 100.0 & 100.0 & 100.0 & 100.0 \\
\hline & 60 & 150 & & 137 & & 581 \\
\hline & \multicolumn{6}{|c|}{ B. Earnings in $1970(\$ 1,000)$, by Shift Type and Age $\S$} \\
\hline Same occ/ind. & 7.49 & 8.57 & 8.63 & 8.50 & 7.41 & 8.47 \\
\hline Same occ/different ind & & & & & & \\
\hline Different occ/same ind. & 8.68 & 11.43 & 12.62 & 10.03 & & 11.29 \\
\hline Different occ/different ind....... & 7.84 & 9.07 & 7.04 & 9.08 & 7.92 & 8.37 \\
\hline
\end{tabular}

* Data are from the 1970 Census 1/100 tape and pertain to the male population in 12 northern SMSAs. Computations are for mail carriers who worked at least 40 weeks in 1970.

+ Occupation/industry code $=331 / 907$.

$\ddagger$ Proportions for an age group refer to 1970 occupation/industry codes of individuals who were mail carriers in 1965 .

$\S$ Entry suppressed where $N<3$. 
TABLE 2

Changes in OCCUPATION/INDUSTRY AFFiliations* DURING 1965-70, BY AgE, For TRUCK DRIVERS IN TRUCKING SERVICES $\dagger$

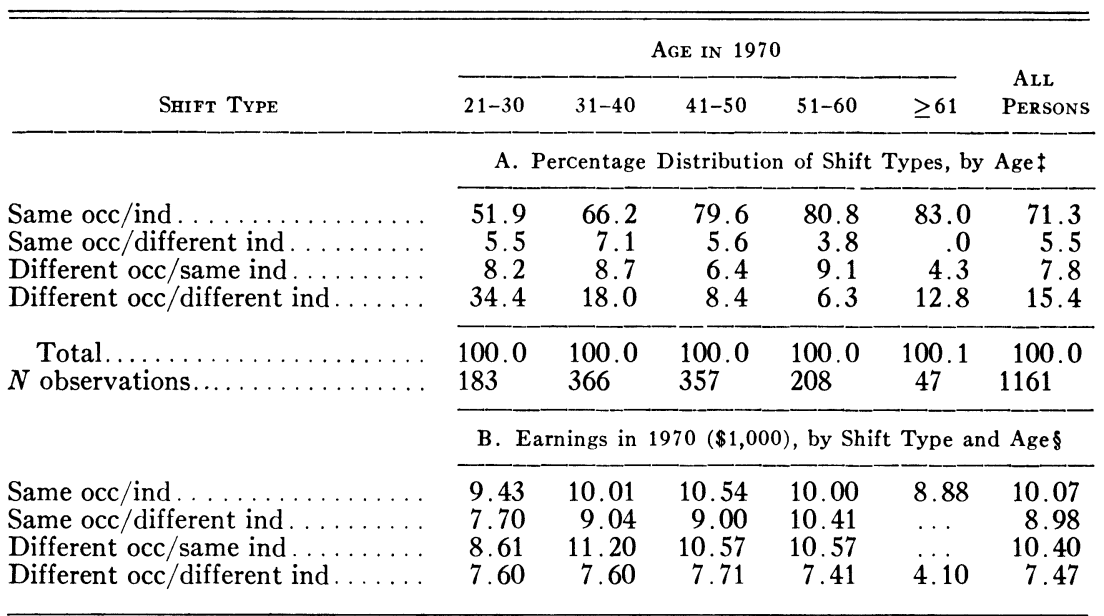

* Data are from the 1970 Census 1/100 tape and pertain to the male population in 12 northern SMSAs. Computations are for truck drivers who worked at least 40 weeks in 1970 .

$\dagger$ Occupation/industry code $=715 / 417$.

$\ddagger$ Proportions for an age group refer to 1970 occupation/industry codes of individuals who were truck drivers in 1965 .

$\S$ Entry suppressed where $N<3$.

panying increase with age in the proportion of stayers in an occupation/ industry position among postal workers and truck drivers, for whom seniority and pension rights are vested with the employer, and the absence of such a trend among carpenters, for whom the craft union (occupation) is the crucial affiliation.

To clarify the significance of these patterns, we report in panel $B$ of the tables mean earnings by age for individuals who have undergone each type of job change. These values speak to the financial returns from making a particular job shift, much as do the curves in panel $B$, figures $2-4$. They are more detailed than the curves in that three sorts of moves are represented; they are less elaborate than the curves in that only earnings five years subsequent to "current" affiliation in the occupation/ industry are reported (equivalent to the first step in the departure curves). The earnings figures reveal substantial disparities in short-term returns from making different sorts of job shifts. What emerges is a situation whereby career-line changes (simultaneous shifts of occupation and industry) are especially detrimental to truck drivers and carpenters, while commonly resulting in an earnings gain, relative to stayers, for letter carriers. In comparison, occupation changes in which the industry affiliation is continued are advantageous to workers in all origin jobs; 
TABLE 3

CHANGES IN OCCUPATION/INDUSTRY AFFILIATIONS* DURING 1965-70, BY AGE, FOR CONSTRUCTION CARPENTERS $\dagger$

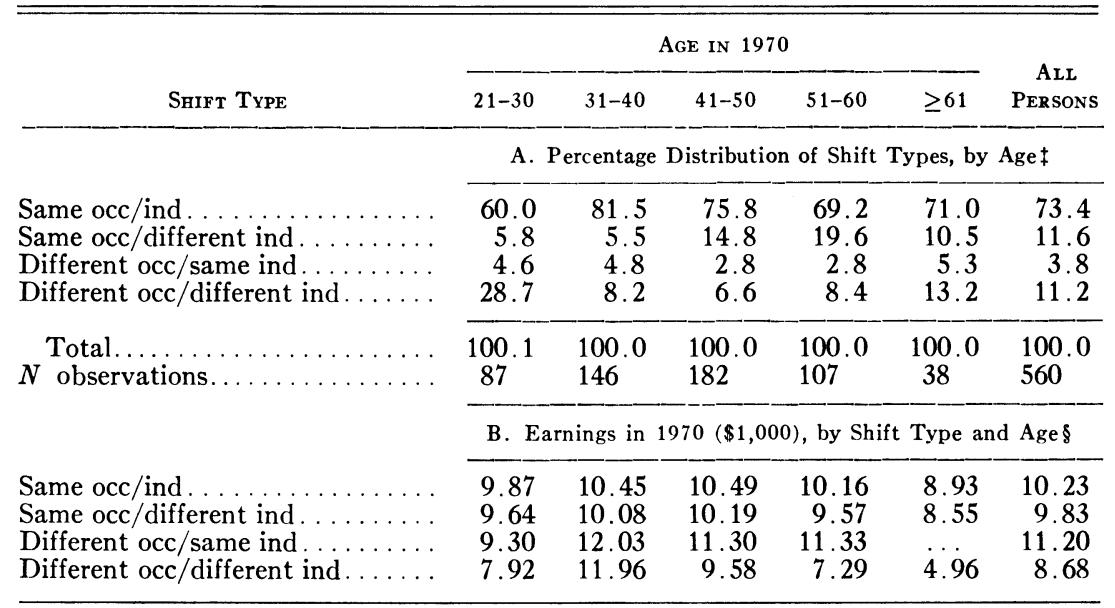

* Data are from the 1970 Census $1 / 100$ tape and pertain to the male population in 12 northern SMSAs Computations are for construction carpenters who worked at least 40 weeks in 1970.

$\dagger$ Occupation/industry code $=415 / 67$.

‡ Proportions for an age group refer to 1970 occupation/industry codes of individuals who were construc tion carpenters in 1965.

$\S$ Entry suppressed where $N<3$.

frequently these shifts denote promotions. Examination of similar data on other occupation/industry positions indicates that there is a general tendency to lower earnings in the short term when a simultaneous change of occupation and industry is made, and to higher earnings when one of these two associations is maintained.

Results analogous to figures 2-4 and tables 1-3 have been calculated for status trajectories; however, no new conceptual points are illustrated, and they are not reported here. With respect to the topic of worker satisfaction, we lack comparable information since measures of satisfaction are not routinely collected in labor force surveys. Yet this omission does not detract from the potential usefulness of satisfaction trajectories for explaining career-line structures, especially age patterns in branch selection and decisions to enter a new line of work in mid-life. Although we do not have data on age variations in satisfaction, we wish to comment on these matters in the context of discussing the related notion of tradeoffs among job features.

Importance of different job facets as a function of age.--In the socioeconomic-achievement literature, the only job features to receive detailed consideration are earnings and occupational status. It is well recognized by researchers who work outside this paradigm, however, that other job facets or dimensions of work are also of concern to individuals (see 
Robinson, Athanasiou, and Head [1969] for a review of the pertinent literature). The actual specification of job facets tends to vary with the interests of a researcher; at a minimum, comprehensive lists include measures of remuneration, status, promotion prospects, job security, task variety, physical difficulty, and opportunity to interact with coworkers. These work dimensions have received some attention by sociologists and economists, especially in recent years (e.g., Blauner 1964; Kohn 1969; Quinn and Shepard 1974; Kalleberg 1975), though the principal studies have been conducted by personnel psychologists (e.g., Roe 1956; Herzberg, Mausner, and Snyderman 1959; Hackman and Lawler 1971).$^{16}$

Scant consideration has been given in these literatures to how the salience of particular job facets might vary with a worker's age. Yet this matter is crucial to understanding career-line branch selection, especially in regard to alterations in the pattern of movement through one's work life. If salience of a job feature to an individual is a function of age, then, even if jobs are viewed, for simplicity, as composed of stable features, ${ }^{17}$ an individual's overall work satisfaction will change as he matures. A job that is attractive to a man of 25 may be quite unrewarding to him at age 50. In particular, we would expect promotion prospects to be an important consideration to a young worker, while physical difficulty of the task and job security should be more pressing concerns to older persons.

Consequently, a different preference mix for job features should pertain to workers of different ages, and to comprehend patterns in job-change behavior over the life cycle it is imperative to ascertain how an individual's trade-off among the job facets evolves through his work life. Related to this consideration is the notion of "career-line vulnerability to aging." By this term we refer to situations in which a person's current job grows increasingly unattractive, possibly because the physical task becomes more difficult as he ages, yet few less demanding positions exist in the career line to which he might transfer. Career-line vulnerability to aging is technology specific and should be particularly common in industries in which a large proportion of employees are engaged in exhausting tasks under harsh conditions (e.g., miners, farm laborers, loggers, sanitation workers). ${ }^{18}$ The possibilities for individuals in such pursuits to continue in the career line through their fifties and early sixties are very limited. Their plight is further exacerbated by the fact that many

16 For a comprehensive review of the various disciplinary approaches to research on job facets, see Temme (1975).

17 This is a useful first approximation for our overview. In actuality, several objective features of jobs (e.g., promotion rate) will vary with employee age. For the narrow purpose of motivating the importance of age contours in job-satisfaction components, it is unnecessary to consider such elaborations.

18 Where a small proportion are in these jobs, aging workers in a firm can often be absorbed in positions set aside for them, such as in janitorial and cleaning services. 
industries with age-vulnerable career structures are located in small communities, frequently one-industry towns, so the workers' prospects of remaining in the labor force, employed at tasks unrelated to the career line, are especially dim.

\section{CAREER-LINE DELINEATION AND CAREER CATEGORIES}

Two strategies for constructing career trajectories from survey data, depending on the sort of information available, are outlined in the first half of this section. In the second half we consider the matter of how to classify detailed career lines and introduce a few illustrative categories which seem well tailored to the objective of linking career-line structures to the socioeconomic attainments of individuals.

Retrospective data collection.-It is our view that to understand the intricate nature of career-line structures, the trajectories should be delineated at a highly disaggregated level. One approach would be to interview a large sample of elderly individuals $(N \approx 50,000)$ about their work histories and use each person's job sequence as a basic datum. Career trajectories could be constructed from these work histories by seeking patterns common to a moderate number of persons. Depending on a researcher's objective, he could utilize either of the perspectives on career-line description outlined in conjunction with figure 1: Individuals who have held a common "key" position (e.g., manager in an auto-manufacturing firm) can be examined to ascertain typical job sequences leading to the position and the most frequent paths followed upon departure. Alternatively, the work histories could be grouped according to entry portal into the labor market (e.g., assembly-line worker in an auto firm), in order to detect the principal paths and branches available to an individual who begins his work life in a particular position and to estimate life-cycle trajectories in earnings, status, and satisfaction as functions of initial location.

We emphasize that the notion of a common work history, essential to accomplishing the foregoing tasks, is very much contingent upon the employment features a researcher chooses to stress. For simplicity, we have limited our discussion to a job specification based on occupation/industry affiliations, but for some purposes it would be appropriate to consider employer shifts as well. In those cases, the delineation of job trajectories would be complicated by the possibilities of employer change in which the occupation/industry is maintained and by industry change in which the employer is maintained, the latter occurring for workers in firms with multiple product lines in different industries. For other analyses it might be advisable to elaborate the concept of a work history by including unemployment intervals or distinguishing between voluntary and involuntary employer separations. In this paper, though, we limit consideration of 
career-line structure to the more tractable case in which work statuses are identified with occupation/industry affiliations.

We should like to point out several difficulties with retrospective data collection as a method for delineating career lines. First, the accounts of early career stages will refer to a labor market which has not been in existence for 20-40 years and therefore may not characterize the career beginnings of individuals currently entering the work force. Second, the earnings figures used in describing the shapes of the remuneration trajectories will be confounded with the effects of inflation through several decades and further complicated by regional differences in wage rates, as many persons will have changed cities and migrated during their work lives. Finally, employment histories which contain multiple job shifts and many earnings changes are especially prone to errors of recall.

Synthetic cohorts. - This approach to career-line delineation can be carried out with an existing data set, the 1970 Census 1/100 sample tape, and we outline the procedure with reference to that file. The 1970 Census has the unusual feature of containing questions on occupation and industry affiliations in 1965 as well as in 1970. Using a very large sample (approximately 150,000 individuals), job-sequence patterns for each occupation/ industry (occ/ind) position (six-digit Census code), as an origin status, can be generated in the following way: We consider the population in a particular occ/ind code in 1965 that is between the ages 18-22-our arbitrary specification of age of entrance into the labor market. As explained, we know a person's job code five years later, in 1970, when he was in the age interval 23-27. By considering other individuals on the tape who in 1965 were in the age range 23-27 and were in the destination occ/ind codes of the first cohort, we can estimate the second-step transitions. This process is continued until the age interval 63-67. At each stage, average earnings and average status are computed, so we can evaluate the typical occupational returns to a person who started in the entry occ/ind during the age period 18-22. Also, the most common destination jobs are enumerated at a transition, permitting points of transfer to other career lines to be identified.

The feasibility of this strategy is not in doubt, though it is well to recognize that the amount of computer time necessary for constructing the career lines is considerable. The earnings trajectories reported in figures $2-4$, incidentally, were generated by the synthetic-cohort procedure. There are a number of advantages to this simulation approach, in comparison with constructing trajectories from retrospective data. First, all stages of the career lines refer to the presently existing labor market; that is, they derive from transitions of individuals during 1965-70. Second, the earnings data associated with each age interval in the life-cycle contours are 1970 figures rather than earnings at times in the distant past. 
There are also difficulties with this approach, in the form of strong assumptions about the evolution of the career process. Foremost is the fact that, with data at only two time points, the probabilities of making various job changes must be viewed as independent of an individual's prior work history; in other words, no account can be taken of the path by which a job was reached or of duration in the position. (Referring back to fig. 1, the assumptions of the synthetic-cohort formulation are equivalent to merging the parallel paths corresponding to a single position, in that this distinctive information is lost.) A second problem with the approach arises from the fact that cohort and age effects are confounded because all individuals in an age group will have entered the labor force at roughly the same time. A final difficulty relates to our data file, though it is not an intrinsic limitation of the simulation procedure. In the 1970 Census, information on employer shifts was not collected; thus the possibility of elaborating the career-line specifications to include employer change is not available. This restriction is especially serious with regard to careers involving craft occupations, since they typically contain considerable movement among employers, and it means that our constructions will be least complete with respect to those positions.

Career-line classification.--If career trajectories were delineated for a large number of entry-level positions, the information could be used in either of two ways. First, remaining at this highly disaggregated level (approximately 10,000 career lines can be constructed with the six-digit occ/ind codes), it would be possible to forecast the evolution of a person's job history and associated earnings and status trajectories from the careerline structure, given his first job codes. Such an undertaking would permit the influence of first position on current status and earnings to be assessed via a formulation which incorporates information about job linkages (see Section V). Second, one could summarize the sorts of career lines present in the labor market and classify the detailed trajectories in terms of the devised categories. This latter kind of endeavor would be useful in discussing career opportunities in different industries, since, for reasons outlined in the next section, career-line features have a basis in industry organization and demography. For the present discussion we assume that the detailed career lines have been delineated, using one of the techniques in the preceding pages, and illustrate the formulation of categories for classifying the trajectories.

We have defined a career line as a collection of jobs (occ/ind codes) in which there is a high probability of movement from one position to another on the list. We specify career trajectory categories by placing further requirements on the pattern of movement and by considering a few additional strategic variables: 
i) An orderly career line $\mathrm{e}^{19}$ has the following properties: If $J_{1}, J_{2}, \ldots, J_{N}$ are the $N$ jobs which constitute the career line, they may be arranged so that $(a),(b)$, and $(c)$ are satisfied.

a) The probability of moving from $J_{n}$ to $J_{n+1}$ exceeds the probability of moving from $J_{n+1}$ to $J_{n}$; that is, movement is predominantly in one direction.

$b)$ If Age $\left(J_{n}\right)$ denotes the average age of workers in Job $J_{n}$, then

$$
\text { Age }\left(J_{n+1}\right)>\text { Age }\left(J_{n}\right) \quad \text { for } n=1,2, \ldots, N-1 \text {; }
$$

that is, older persons, on average, tend to be found in each succeeding position.

c) If $\operatorname{Earn}\left(J_{n}\right)$ denotes average earnings in job $J_{n}$ and if $\operatorname{Stat}\left(J_{n}\right)$ denotes status of job $J_{n}$, then

and

$$
\operatorname{Earn}\left(J_{n+1}\right)>\operatorname{Earn}\left(J_{n}\right) \quad \text { for } n=1,2, \ldots, N-1,
$$

$$
\text { Stat }\left(J_{n+1}\right)>\operatorname{Stat}\left(J_{n}\right) \quad \text { for } n=1,2, \ldots, N-1 .
$$

Thus each successive position in an orderly career line brings an improvement in earnings and status, exactly what one should wish from a work career. ${ }^{20}$

ii) A chaotic career line is a collection of positions characterized by (a) the absence of a unilineal progression-individuals tend to cycle among the positions; $(b)$ a similar average age of workers in each jobthere is no age hierarchy because no job is a prerequisite for another on the list; $(c)$ a large standard deviation of worker ages in each jobgreater than the standard deviation of ages in jobs which constitute an orderly career; and $(d)$ little difference in average earnings or status among the positions. This sort of trajectory can usefully be viewed as an array of activities requiring few special skills that might be obtained through prior employment in the career line, so each job serves, in practice, as an entry portal for new workers. These positions have been termed "dead-end" jobs by Liebow (1967).

iii) A craft career line and a professional career line are both characterized by low probabilities of occupational change over the life cycle and by large age standard deviations in the principal job. Some career features which serve to differentiate between the two categories concern amount of out-mobility and shape of the earnings trajectory. Occupational

\footnotetext{
19 More precise terminology would refer to career-line path, as specified in Section II. To keep jargon to a minimum, we use the generic term "career line" where confusion is unlikely.

20 For the purpose of investigating the association between job-sequence structure and career rewards, the categories could be defined apart from the earnings and status trajectories; that is, solely on the basis of job-shift pattern and age relations.
} 
change is more common in craft employment, especially at later ages when foreman jobs become available as an alternative to manual labor. Also, the earnings contours of professionals are likely to involve a steep rise early in work life, while the wage structure in craft occupations shows little responsiveness to seniority (Hall 1975, p. 189). Yet there are numerous exceptions; in the main, craft and professional career lines must be differentiated through factors that are not the building blocks of career trajectories. They must be distinguished on the basis of institutional considerations such as the extent to which the "professional model" (ibid., p. 72) is satisfied. This subject, of course, is very much within the realm of occupational sociology, and it should not be surprising that one must draw upon the traditional literature to supplement the ability of a few structural variables (job-sequence pattern and reward trajectory) to distinguish among career types.

Indeed, the career-line features that have occupied our attention in this paper depict what properly may be termed the "skeleton" of work experience. The trajectories must be fleshed out with accounts of the variety of institutional settings within which employment is contracted and work is performed, supervised, and motivated. Careers are intimately associated with considerations of job content, stability of employment, worker-management relations, and employee associations-matters on the fringe of career-line structure yet crucial to specifying the quality of an individual's work experience over the life cycle. It is these topics to which the literatures of occupational sociology, labor economics, and industrial relations are attuned.

\section{INDUSTRIAL DETERMINANTS OF CAREER-LINE STRUCTURES}

The industry entered by a young worker carries considerable consequence for the evolution of his earnings and status. ${ }^{21}$ This is because industries differ in social organization and demography in several important respects-promotion rules, occupational composition, rate of employment growth ${ }^{22}$-and each of these factors influences the structure of the career lines which emerge from an entry-level position. With respect to promotion rules, the degree to which skilled and white-collar jobs are filled by upgrading employees, rather than by hiring directly into vacant positions from outside the firm, impinges in an obvious way on the

21 Pertinent material on the relation between first job and subsequent career development may be found in Lipset and Malm (1955), Freedman (1969), and Ornstein (1976). 22 While these variables operate at the level of the firm, we emphasize industry because it is a more useful analytic construct. Firms in the same industry are likely to have comparable technologies and organizational forms and would be subject to identical fluctuations in demand for their products. For this reason much of the interfirm variation in career-line structures is likely to derive from industry differences. 
presence of upward-leading branches. The institutional rules governing mobility in a firm derive from the magnitude of the skill gap separating occupational levels, from historical circumstances surrounding the industry's founding (Stinchcombe 1964, pp. 153-64), and from union contracts which specify promotion, demotion, and transfer districts (Doeringer 1967; Kerr 1954).

In many industries occupational composition is linked closely to technology. Some (e.g., chemical processing) contain high ratios of skilled/ semiskilled workers, while other industries (e.g., textile manufacturing) are organized around tasks requiring a predominantly semiskilled labor force. Other considerations being equal, we expect more favorable advancement prospects for, say, a low-skilled worker to exist in the former setting. With respect to rate of employment growth, expanding industries would be generating new skilled and white-collar positions, which could be filled through promotion. In contrast, where employment is stable or declining (e.g., railroad transportation), few upper-status slots are likely to be available, and the waiting time for promotion would be long.

Thus, for many a worker, industry affiliation is an important determinant of the sort of career he will have. Individuals do change firm and industry, yet after the initial years of employment such shifts are not without attendant costs. Investments have been made in seniority, providing job security and a place in the promotion queue, and rights to a pension have accumulated. Ordinarily these benefits must be relinquished when changing employers. Also, many work skills are technology specific and have little transfer value to other industries. Sofer (1970, p. 4) summarizes these considerations eloquently: "Initial entry into a particular occupation or structure sets an investment going, an irreplaceable quantum of time is put into a particular job or career and not to follow through means a loss of the investment. A realized misinvestment and an attempt to correct it necessitates a new start and a falling behind in competition within our age-graded stratification and mobility structure."

The preceding account of the contribution of firm and industry to career-line structure is complicated by the unique circumstances of a few career lines. In the salaried professions, ${ }^{23}$ crafts, and "secondary" labor market positions (Doeringer and Piore 1971), the salience of employer characteristics is much reduced. In the professions, mastery over a body of knowledge of wide applicability (i.e., not firm specific), confirmed by educational credentials and matured by practice, permits employers to give credit for prior work experience in an offer of salary and rank to a job applicant. This makes for a national labor market in a specialty such

23 The "free professions" (law, medicine) provide another instance in which firm affiliation carries little consequence. Because this is due largely to the self-employed nature of these pursuits and because the careers are treated in detail in the occupational sociology literature, we do not discuss them here. 
as electrical engineering and a relatively small variance across firms in salaries for individuals with comparable backgrounds. (There are some professions, however, in which, for reasons of custom, little consideration is given to work experience in a job offer. Public school systems, for example, commonly require newly hired teachers to begin at the lowest salary rung. In this situation, mobility between firms is lessened, and the importance of employer as a determinant of earnings and other careerline features is much enhanced. ${ }^{24}$

For individuals in construction and other crafts (longshoremen, printing trades workers), firm affiliation is also a matter of low consequence as a determinant of career-line features. Level of remuneration and other work arrangements are matters under the control of the craft union. Within a local labor market wages are equalized for union members, so no worker need prefer one employer to another. Productivity may also be standardized so that no employer need show a preference for any worker (Kerr 1954). Employment is frequently intermittent; in construction, association with a firm often lasts no longer than the project being erected. A worker obtains his security from the union, which controls the supply of labor and shields members from competition with outsiders (Stinchcombe 1959). Careers, in this circumstance, tend to evolve within the occupation and are little influenced by employer characteristics.

The "secondary" sector shares with the preceding occupational categories a low relevance of firm and industry for career prospects. It differs from them in a lack of employee leverage. In the professions, leverage derives from mastery over a body of knowledge that is transferable among firms; in the craft occupations, leverage results from labor contracts which restrict hiring to union members. In comparison, the secondary labor market consists of unskilled, low-paying jobs, in which workers lack the protection of a powerful union. These jobs are not components of coherent career lines and hold out little possibility for advancement. In the vernacular of dual labor market theorists (Doeringer and Piore 1971), employers make no investment in the workers, such as acquainting them with complex procedures of importance to the firm. Employees of long service, consequently, are interchangeable with new hires and need not be paid above the market wage. Firm and industry characteristics are of little salience because workers in secondary jobs do not accrue seniority rights which might bind them to an employer. From the perspective of

24 As an illustration of the effects of these different labor market arrangements, consider 1970 median earnings figures for electrical engineers and secondary school teachers in different SMSAs. For Los Angeles, New York City, Houston, and Charleston, the pairs of figures are, respectively, $(\$ 14,404 ; \$ 11,246),(\$ 14,266 ; \$ 10,985),(\$ 13,172$; $\$ 8,113)$, and $(\$ 13,129 ; \$ 7,372)$. For electrical engineers the range is approximately $\$ 1,300$; for school teachers, despite a lower average, the range is much greater, nearly $\$ 4,000$. Data are from U.S. Bureau of the Census (1973, table 175). 
career structure, the "chaotic" career line, specified in Section III, provides one illustration of the movement of individuals among these jobs. ${ }^{25}$

Segmented labor markets. - The view of the labor market as consisting of "primary" and "secondary" sectors is developed in the writings of neo-institutional economists (Doeringer and Piore 1971; Reich, Gordon, and Edwards 1973). In capsule form, dual theorists argue that certain jobs (the primary sector) are organized around internal labor markets. Here entrance into a firm occurs at the lowest occupational rung, and entrants are insulated from nonemployees (the external labor market) in competing for promotion and salary. The sorts of jobs for which an internal labor market will exist are ones which require employers to invest in workers, training them for complex tasks. High remuneration and good advancement prospects are afforded as incentives to remain with the firm and because the skills acquired make for more productive and hence more valuable employees. In contrast, as indicated above, the secondary sector consists of positions for which an employer chooses not to upgrade worker capabilities.

In our opinion, the dualists' view of the labor market, structured by custom and institutional arrangements, is a more accurate characterization than the "human capital" perspective. According to the latter formulation (which, incidentally, underlies the socioeconomic-attainment models of sociologists), wage differentials for persons of similar training and ability tend to narrow with time, since employers will offer no more than necessary for workers in a skill category, and employees will change jobs if they can earn more in another firm. Thus, a market wage emerges. Dualists argue that this model does not depict wage and mobility patterns in the primary sector, where internal labor markets shield workers from competition with nonemployees while binding them to the firm through an accumulation of seniority entitlements. Yet, despite the dualists' sensitivity to institutional factors, theirs is a bare-bones description, in which the considerable variety of labor market structures is reduced to the distinction between primary and secondary jobs.

More elaborate institutional accounts speak of a "segmented" labor market (Cairnes 1888, pp. 60-69; Kerr 1954), recognizing that there exist multiple noncompeting groups. Little has been written, though, by

25 The age at which an individual enters a secondary labor market position is a consideration of immense importance. Young unskilled workers often begin their careers in such a job (e.g., gas station attendant, busboy in a restaurant) but move into orderly career lines while young and able to perform demanding physical tasks. Also, individuals may terminate their work lives in secondary labor market positions, if the activities they have pursued are "age vulnerable." These comments pertain to workers who spend the bulk of their lives in orderly career lines. Those who, for one reason or another, enter secondary jobs in mid-life may find themselves unable to secure subsequent employment in the primary sector and would be restricted to cycling among "dead-end" jobs. 
way of characterizing these segments. Yet it should be evident from Section II that career lines have the features of internal labor markets, in that the associated labor pools are distinct and insulated from one another through the presence of separate seniority ladders. ${ }^{26}$ Indeed, the career line represents the smallest labor market unit with this property. ${ }^{27}$ The primary sector can therefore be usefully viewed as consisting of multiple internal labor markets, which are, concretely, career lines. We also expect the secondary sector to be made up of several distinct labor markets, as workers will restrict their drifting among jobs to related positions (e.g., individuals who cycle among restaurant, cafeteria, and hotel work are probably not the ones who move among jobs in hospitals and nursing homes). Thus, even without institutional barriers to inhibit movement, habit and familiarity will engender labor market segmentation and the possibility of wage differentials for essentially similar tasks, performed by workers with identical qualifications.

In Section III we presented criteria for categorizing career lines in which common features of the trajectories were emphasized. A second way to group career lines is by the principal industry each is in. This manner of aggregation arranges the trajectories according to similar "vulnerabilities" and other organizational properties, in recognition of the fact that unemployment rate, seasonal variability in employment, and product competition-as well as promotion rules and prognosis for long-term growth-are industry effects and influence salary and worker experiences in all affiliated career lines.

As a result of such considerations some industries will have many positions which are "dead-end" in terms of advancement prospects, although the jobs belong properly to the primary sector. That is, if we identify an internal labor market with a situation in which seniority entitlements bind a firm to its workers and workers to the firm, internal labor markets will exist even where the potential for earnings growth and promotion is no better than in the secondary sector. This situation is likely in declining industries, where employees with many years of experience might choose to remain despite poor advancement prospects. Some dualists (e.g.,

26 In reality, the degree of insulation of different career lines can be arranged on a continuum. As we have indicated, some have a unique entry portal and may even have an age ceiling for applicants, all but obviating the possibility of entering after long employment in an unrelated job. Other career lines are more permeable, having several entry portals. For simplicity, in this brief discussion, we argue from the approximation of autonomous segments.

27 Dunlop (1964, pp. 16-17) speaks of a "job cluster" as the smallest building block in the wage structure. His concept is not coterminous with career line but refers to a variety of work contexts in which individuals compare their wage rates, whether in the same seniority track or not. Piore (1975, pp. 128-30) has recently introduced the notion of a "mobility chain." Though his discussion is brief, he employs that term much as we do "career line," to describe job linkages. 
Piore 1971, p. 92; Vietorisz and Harrison 1973) identify the primary sector with jobs holding out possibilities for earnings growth as well as employment stability. We suggest, however, that the crucial consideration is the degree to which workers accumulate nontransferable benefits and that the wage implication of segmented labor markets is principally one of a considerable variation in earnings for persons with comparable training, performing similar tasks, in different firms. This should be true especially of older workers; the wage-setting mechanism can proceed for them with little regard to the market wage or salaries in other industries and thereby can reflect more intensely considerations of custom, equity among employees who interact, ${ }^{28}$ and the financial cost to the firm of a generous wage policy.

In summary, the "segments" in dual labor market theory are, concretely, career lines; whether a particular position should be assigned to the primary or secondary sector depends on industry rules governing returns to seniority and on union rules concerning the privileges of membership. Further, career lines in the primary sector with similar entrance requirements, in different industries, may be associated with diverse reward trajectories, as these segments are insulated from one another, not only from the secondary sector. This intricate patterning of the labor market by career trajectories carries considerable consequence for the contribution of individual-level variables (especially educational attainment) to socioeconomic achievement, an issue to which we now turn.

\section{CAREER LINES AND THE ATTAINMENTS OF INDIVIDUALS}

A major difficulty with current models of the socioeconomic-achievement process (e.g., Blau and Duncan 1967; Jencks et al. 1972; Sewell and Hauser 1975) is that they ignore the rich texture in labor market structure which we have been describing. Jobs, in that literature, are treated implicitly as independent entities rather than as linked components of coherent trajectories. ${ }^{29}$ As a consequence, the models are insensitive to the fact that changes in status and earnings for an individual, from first job to current job, are to some extent "scheduled," consequent upon the

28 Commenting on industry differences in the wages of truck drivers, Dunlop (1964, p. 21) writes, "Teamsters hauling oil and building materials come in contact with high paid employees in their work operations, while laundry and scrap drivers have more contact with low paid employees." In a similar vein, Thurow $(1975$, p. 108) remarks that bargaining over relative wages is as common as bargaining over absolute wages.

29 Attempts to incorporate the career concept into the socioeconomic-attainment paradigm are reported in Blau and Duncan (1967, pp. 177-88), Featherman (1971b), and Kelley (1973). The linkages in those models concern the perpetuation of status and earnings, but they do not involve an explicit consideration of movement patterns among detailed jobs. 
career line's reward trajectories. To the degree this is true, the impact of education and other background characteristics on status and earnings over the life cycle should be investigated in terms of the latitude afforded these variables in particular career lines.

In our imagery, then, individuals enter a career line early in their work lives. From that point in time they become progressively rooted, as investments accumulate, and follow along one of its paths. Because of labor market segmentation and the divergent forces acting on various industries, life-cycle trajectories in earnings and status can differ dramatically among career lines, even for persons with equivalent backgrounds. There are a couple of implications of this formulation of labor market structure for the attainments of individuals that we wish to explore at this juncture: the way education (and other background variables) "pays off" or fails to do so and the considerable importance of career-line choice.

Education gets converted into status and earnings not in some vague or random manner but in relation to career lines. This transformation is accomplished in one of two ways; education can serve as a qualification for admission into a career line, or it can pay off continuously over the life cycle. Education is well recognized as an entry credential with respect to professions which require specialized training (e.g., medicine, law). However, educational attainment of a general nature is also requisite for admission into less elite occupations. For instance, police and fire departments commonly insist on a high school diploma for employment. It is worth remarking that in these career lines, once a person is hired, advancement depends little on education level beyond the entrance minimum. Instead, advancement is scheduled largely in terms of seniority, as bureaucratic procedures and union contracts limit the ability of employers to reward workers on the basis of background characteristics or performance.

A second way in which education can pay off in earnings and status is by advantaging workers in a career line who have high levels of schooling. For example, firms that employ engineers may hire B.A. and M.A. graduates for the same tasks, though at slightly different starting salaries. They are soon sorted out, however, as those with advanced credentials commonly prove to be more qualified for promotion. ${ }^{30} \mathrm{~A}$ similar situation exists in public school systems. Individuals with varying levels of education above the entrance minimum can become teachers (i.e., they enter at the same status level). It is probably the more educated, though, who later advance to the posts of department chairman and principal.

Education, then, provides status and earnings rewards through facilitating access to valued career lines, through differentiating among entrants with respect to rate of advancement, or through a combination of both. 30 This comment is based on observations by the author while working for IBM. 


\section{American Journal of Sociology}

These different functions of education are not distinguished in socioeconomic-attainment models, as no recognition is given to career-line structures. What are calculated in those models are average returns to education in first job and current job, the averages being taken over individuals in career lines with diverse features-in which education pays off in different amounts and in different ways. What is sacrificed in such a formulation is a comprehension of the mechanism by which background variables operate, because the mechanisms are well defined only at the disaggregated level of the career line. Omission of these structures is unfortunate for several reasons. First, career lines are persistent and relatively stable, not evanescent phenomena which might properly be treated as "random effects." Second, they constitute an intermediary structure, relating the behaviors and life chances of individuals to "macro" organizational units, thereby linking two important levels in sociological analysis. Third, career lines should prove useful in understanding racial and ethnic disparities in earnings and status, a matter upon which we comment briefly later in this section.

The determinants of career-line entrance loom large in our analysis since we view entrance as tantamount to launching an individual on earnings and status trajectories, heavily scheduled in terms of seniority in some career lines, open to influence by education and role performance in others. While education is one consideration in securing entrance, it is the case that a variety of career lines are open to persons with the same level of general education. A high school diploma, for example, does not signify whether an individual will accept employment in a textile factory, in a primary-metals-manufacturing plant, or on an assembly line. Yet the consequences of this choice are substantial, as the career lines associated with the various entry positions differ considerably in their features.

One major determinant of this choice is community of residence. Many cities have a limited range of industrial sectors and, because career-line features are to a large degree a consequence of industry organization, a limited variety of career-line structures. This is a crucial matter with respect to one-industry towns. Mining communities and mill towns have restricted career opportunities, as these appellations suggest. What is less appreciated is the tendency to industry concentration in relatively large cities. In Akron, Ohio, 37\% of the male labor force in manufacturing is employed in rubber-products plants; in Wilmington, Delaware, 45\% are in chemical and petroleum processing; and in Birmingham, Alabama, the corresponding figure in primary and fabricated metals is 53\% (U.S. Bureau of the Census 1973, table 184). The vulnerability of such communities to cyclical variations in product demand, which give rise to wide swings in the unemployment rate, is well known. What is not recognized 
is the pervasive effect of industry concentration on career-line choice by young workers. Individuals do migrate to obtain better jobs, but this involves attenuating ties to friends and relatives, and many surely choose to sacrifice career prospects instead.

A second array of factors influencing career-line entrance relates to friendship patterns and ethnicity. With community of residence and educational attainment as givens, we can still identify systematic determinants of job selection. Friendship is important as a source of knowledge about job openings; it has been remarked (e.g., Freedman 1969, pp. 29-31) that low-skilled workers often obtain employment through personal contacts. Ethnicity is consequential partly because friendship networks tend to remain within ethnic boundaries. However, the ethnic patterning of the labor force is more pervasive than can be accounted for by friendship referrals. For various historical reasons certain career lines have come to be associated with particular ethnic groups; in New York City, for instance, the Irish are overrepresented among policemen, Italians among sanitation workers, and the apparel trades have been traditionally a Jewish preserve. Thus, even within a single labor market, structural factors direct individuals with equivalent educational qualifications into different career lines.

Ethnic stratification.-We wish to emphasize that our formulation carries particular consequence for an understanding of ethnic and racial differences in earnings and status. In part, these differences can be explained in terms of level of educational attainment (Duncan and Duncan 1968), though it is the case that, holding constant education and other background variables, sizable disparities are still observed (Duncan 1969; Featherman 1971a). We suggest that much of these residual effects is due to the career-line affiliations of the ethnic groups, as some are concentrated in work settings with poor earnings and status trajectories and low returns to education.

The reason why ethnic groups are differentially represented in career lines stems from a number of factors. In some instances discrimination is of paramount importance; the exclusion of blacks, for example, from the construction trades requires no documentation at this point in our history. A second factor concerns tradition and custom, though it also taps discriminatory practices. In this regard we have mentioned the concentration of Irish in police departments and Italians in sanitation work. A third consideration, frequently neglected, relates to the locations of ethnic groups in particular regions and communities. Since industries are also concentrated geographically, the various ethnic groups tend to be exposed to different career-line structures. As examples of ethnic concentration by industry, in 1950, individuals of French-Canadian extraction were overrepresented in textile mills by a factor of 7 , and 
persons of Czechoslovakian and Yugoslavian parentage were employed in metal-processing plants at four times their rates in the country (Hutchinson 1956, pp. 224-31). ${ }^{31}$ In each case, the employment pattern resulted from an ethnic concentration in communities where the industry constitutes a principal economic activity.

The matter to be emphasized is that, along with discriminatory practices, community of residence serves to channel ethnic and racial groups into different career lines, which often contain divergent opportunity structures. For this reason we suggest that career-line affiliation is a salient factor in understanding ethnic and racial disparities in status, earnings, and unemployment rates. Viewed generally, disadvantage can come about in two ways: by means of barriers to career-line entrance and by unequal payments for the same work. Both considerations surely contribute to the disparities among ethnic groups, and their relative importance must be evaluated in the cases of specific groups in order to develop effective programs of redress. Our analysis is oriented to the former consideration. In this regard, we have stressed the matter of residence, which, incidentally, has been shown to be relevant to ethnic differences in occupational standing in another society (Spilerman and Habib 1976).

Assessing the role of background variables in a labor market patterned by career lines.-Drawing together our remarks in earlier sections, we conclude by outlining several modifications of the basic socioeconomicachievement model which would permit ascertaining both the impact of career-line structures on the status and earnings of individuals and the particular role of education in a labor market patterned by career lines. Our proposals center on clarifying the contribution of education (and other background variables) to career-line entrance and to earnings and status advancement subsequent to entrance.

In socioeconomic-achievement models, status and earnings of first job are commonly regressed against an individual's background characteristics, in order to assess the latter variables' contributions to early labor force attainment. However, if in choosing an initial position individuals are selecting career lines rather than autonomous jobs, status and earnings of first job would constitute a poor estimate of the true value of the entered position. In particular, many career lines which pay well after the initial years of employment begin a new worker as an apprentice or in some equivalent low-ranked and low-salaried position. The immediate rewards of such a job are not what a worker has selected; rather, it is the prospects for advancement which are scheduled into the positions.

31 The figures are for operatives. Ethnic proportions of total employment in an industry are not reported by Hutchinson. 
Therefore, to ascertain the contribution of background variables to initial job choice, we suggest replacing status and earnings of first job by representative measures of the career line's worth, such as expected lifetime earnings and expected status 20 years after career-line entrance. (These values could be generated by the simulation procedure described in Section III.) The additional impact of background variables on earnings in first job would be ascertained by investigating the determinants of the difference between an individual's earnings and the mean earnings of all persons of the same age in the identical position.

An assessment of the contribution of education and other background characteristics to securing career-line entrance is made complicated in national samples by the fact that career lines of a particular quality are not distributed uniformly in the country but are concentrated by region and community. Probably the most accessible way to hold career-line opportunity constant is to characterize each worker in a study by the industry distribution in the locale of his first job. This could be accomplished through introducing a set of regressors that summarize the employment proportions in various industry categories. Controlling in this manner for industry composition adjusts for differences in career-line availability via the argument that industry organization is a principal determinant of career-line features. ${ }^{32}$

The impact of education on status and earnings at points subsequent to career-line entrance can be investigated through use of the "expected" levels of the occupational-attainment variables. The expected values would be career-line forecasts, based now on an individual's first job codes ${ }^{33}$ and his time in the labor force, and could be generated by the simulation procedure. $^{34}$ To ascertain the contribution of education to current status and earnings, net of its effects on career-line entrance, one would regress the difference between current status and the career-line forecast of current status, or current earnings and the career-line forecast of current

32 In analyses of earnings from national samples we further recommend that the community wage level be controlled. This would reduce the error variance in explanations of individual earnings, as the same job often brings diverse salaries in different cities (see, e.g., n. 24 regarding the earnings of secondary school teachers). In addition, because some industries are geographically concentrated, occupations that are overrepresented in them may be associated with high wage rates or low wage rates because of location; i.e., apart from their human capital requirements.

33 We refer to first (full-time) job because this position is characteristically used as a measure of early attainment (e.g., Blau and Duncan 1967). Our investigations suggest, however, that jobs held in the first few years after labor force entrance are heavily experimental. Use of "job held three years after labor force entry" would cut down much of the noise in forecasting current attainment from career-line trajectories.

34 Since the expected values would be computed using a data set different from the sample under investigation, they would not be attributable to the background characteristics of individuals in the sample. 
earnings, on temporally preceding variables. ${ }^{35}$ In our formulation, the background characteristics can account directly for only this discrepancy.

Finally, we point out that even this modified model of socioeconomic attainment, if applied to a representative sample from a heterogeneous population, is subject to the criticism that the parameter estimates are averages over individuals in career lines with diverse properties, in which education pays off in different ways. We therefore suggest that the achievement process, post entrance to a career line, is better approached through disaggregating the population and estimating separate equations for the subsamples. In particular, career lines should be classified into a small number of relatively homogeneous categories with respect to their main features. On the basis of this classification, individuals in a survey should be assigned to one or another subsample according to the career line of their first job, and the determinants of current status and earnings should be estimated for each subsample. The population-level model could be constructed as a composite of these subsample models, among which the parameter estimates would presumably be quite different, as they would mirror the variety of mechanisms associated with attainment in the various types of trajectories.

\section{REFERENCES}

Becker, Gary S. 1964. Human Capital. New York: Columbia University Press.

Blau, P., and O. D. Duncan. 1967. The American Occupational Structure. New York: Wiley.

Blauner, R. 1964. Alienation and Freedom: The Factory Worker and His Industry. Chicago: University of Chicago Press.

Cairnes, John E. 1888. Some Leading Principles of Political Economy Newly Expounded. New York: Harper.

Caplow, Theodore. 1954. The Sociology of Work. New York: McGraw-Hill.

David, Martin. 1969. "Time-Series versus Cross-section Lifetime Earnings Patterns in Different Occupational Groups." Pp. 664-67 in Proceedings of the Business and Economics Section of the American Statistical Association, 1969. Washington, D.C.: American Statistical Association.

Doeringer, Peter. 1967. "Determinants of the Structure of Industrial Type Internal Labour Markets." Industrial and Labour Relations Review (January), pp. 206-20. Doeringer, Peter, and Michael Piore. 1971. Internal Labor Markets and Manpower Analysis. Lexington, Mass.: Heath Lexington.

35 In carrying out this regression, a term for the career-line forecast of the dependent variable should be included as a regressor. An equivalent formulation would be

$$
y_{i}=f\left(x_{1 i}, \ldots, x_{n i}, \hat{y}_{i}\right)+\epsilon_{i},
$$

where $y_{i}=$ current status (or earnings) for individual $i ; \hat{y}_{i}$ is the career-line forecast of $y_{i} ; x_{1 i}, \ldots, x_{n i}$ are temporally preceding variables; and $f$ denotes a linear relation. Since $\hat{y}_{i}$ is presumably a function of institutional features (e.g., occupational distribution of the industry, growth rate, promotion rules), an approximation to using the career-line forecast as a regressor would be to replace $\hat{y}_{i}$ by measures of institutional characteristics. 


\section{Careers and Labor Market Structure}

Duncan, Beverly, and Otis D. Duncan. 1968. "Minorities and the Process of Stratification." American Sociological Review 33 (June) : 356-64.

Duncan, Otis Dudley. 1969. "Inheritance of Poverty or Inheritance of Race." Pp. 85110 in On Understanding Poverty, edited by Daniel P. Moynihan. New York: Basic.

Duncan, Otis Dudley, David L. Featherman, and Beverly Duncan. 1972. Socioeconomic Background and Achievement. New York: Seminar.

Dunlop, John T. 1964. "The Task of Contemporary Wage Theory." Pp. 3-27 in The Theory of Wage Determination, edited by John T. Dunlop. London: Macmillan.

Featherman, David L. 1971a. "The Socioeconomic Achievement of White ReligioEthnic Subgroups: Social and Psychological Explanations." American Sociological Review 36 (April): 207-22.

- 1971b. "A Social Structural Model for the Socioeconomic Career." American Journal of Sociology 77 (September): 293-304.

Fichter, Joseph. 1961. Religion as an Occupation. South Bend, Ind.: University of Notre Dame Press.

Form, William H., and Delbert C. Miller. 1949. "Occupational Career Patterns as a Sociological Instrument." American Journal of Sociology 54 (January): 317-29.

Freedman, Marcia. 1969. The Process of Work Establishment. New York: Columbia University Press.

Glaser, Barney G. 1964. Organizational Scientists: Their Professional Careers. Indianapolis: Bobbs-Merrill.

Goldner, Fred. 1965. "Demotion in Industrial Management." American Sociological Review 30 (October): 714-24.

Hackman, J. Richard, and Edward E. Lawler III. 1971. "Employee Reactions to Job Characteristics." Journal of Applied Psychology Monograph 55, no. 3 (June): 259-86.

Hall, Oswald. 1948. "The Stages of a Medical Career." American Journal of Sociology 55 (November) : 243-53.

Hall, R. T. 1975. Occupations and the Social Structure. 2d ed. New York: McGraw-Hill.

Hanoch, Giora H. 1967. "An Economic Analysis of Earnings and Schooling." Journal of Human Resources 2 (Summer): 310-29.

Henslin, James. 1968. "Trust and the Cabdriver." Pp. 138-58 in Sociology and Everyday Life, edited by Marcello Truzzi. Englewood Cliffs, N.J.: Prentice-Hall.

Herzberg, F., B. Mausner, and B. Snyderman. 1959. The Motivation to Work. New York: Wiley.

Hodge, Robert W., and Donald J. Treiman. 1966. "Occupational Mobility and Attitudes toward Negroes." American Sociological Review (February), pp. 93-102.

Hutchinson, E. P. 1956. Immigrants and Their Children, 1850-1950. New York: Wiley.

Janowitz, Morris. 1960. The Professional Soldier: A Social and Political Portrait. New York: Free Press.

Jencks, C., M. Smith, H. Acland, M. J. Bane, D. Cohen, H. Gintis, B. Heyns, and S. Michelson. 1972. Inequality. New York: Basic.

Kalleberg, Arne. 1975. "Work Values, Job Rewards and Job Satisfaction: A Theory of the Quality of Work Experience." Ph.D. dissertation, University of WisconsinMadison.

Kelley, Jonathan. 1973. "Causal Chain Models for the Socioeconomic Career." American Sociological Review 38 (August): 481-93.

Kerr, C. 1954. "The Balkanization of Labor Markets." Pp. 92-110 in Labor Mobility and Economic Opportunity, edited by E. W. Bakke, P. M. Hauser, G. L. Palmer, C. A. Myers, D. Yoder, and C. Kerr. New York: Wiley.

Kohn, M. 1969. Class and Conformity. New York: Dorsey.

Liebow, Elliot. 1967. Tally's Corner. Boston: Little, Brown.

Lipset, Seymour M. 1960. Political Man. New York: Doubleday.

Lipset, Seymour M., and R. Bendix. 1952a. "Social Mobility and Occupational Career Patterns. I. Stability of Job Holding." American Journal of Sociology 57 (January): 366-74. 
1952b. "Social Mobility and Occupational Career Patterns. II. Social Mobility." American Journal of Sociology 57 (March): 494-504.

Lipset, S. M., and F. T. Malm. 1955. "First Jobs and Career Patterns." American Journal of Economics and Sociology 14 (April): 247-61.

Mincer, J. 1974. Schooling, Experience, and Earnings. New York: Columbia University Press.

Ornstein, Michael D. 1976. Entry into the American Labor Force. New York: Academic Press.

Palmer, Gladys. 1954. Labor Mobility in Six Cities. New York: Social Science Research Council.

- 1957. "Attitudes toward Work in an Industrial Community." American Journal of Sociology 63 (July) : 17-26.

Parnes, Herbert S., and Gilbert Nestel. 1974. "Middle-aged Job Changers." Pp. 79-114 in The Pre-Retirement Years, edited by H. S. Parnes, A. V. Adams, P. Adrisani, A. I. Kohen, and G. Nestel. Vol. 4. Columbus: Center for Human Resource Research, Ohio State University.

Piore, Michael J. 1971. "The Dual Labor Market." Pp. 90-101 in Problems in Political Economy, edited by David Gordon. Lexington, Mass.: Heath.

- 1975. "Notes for a Theory of Labor Market Stratification." Pp. 125-50 in Labor Market Segmentation, edited by Richard C. Edwards, Michael Reich, and David M. Gordon. Lexington, Mass.: Heath.

Quinn, Robert P., and Linda J. Shepard. 1974. The 1972-73 Quality of Employment Survey. Ann Arbor: Survey Research Center, Institute for Social Research, University of Michigan.

Reich, Michael, David M. Gordon, and Richard C. Edwards. 1973. "A Theory of Labor Market Segmentation." American Economic Review 63 (May): 359-65.

Reynolds, L. G. 1951. The Structure of Labor Markets. New York: Harper.

Ritzer, George. 1972. Man and His Work: Conflict and Change. New York: AppletonCentury-Crofts.

Robinson, John P., Robert Athanasiou, and Kendra B. Head. 1969. Measures of Occupational Attitudes and Occupational Characteristics. Ann Arbor: Survey $\mathrm{Re}-$ search Center, Institute for Social Research, University of Michigan.

Roe, Anne. 1956. The Psychology of Occupations. New York: Wiley.

Sewell, W. H., and R. M. Hauser. 1975. Education, Occupation and Earnings. New York: Seminar.

Slocum, W. 1966. Occupational Careers. Chicago: Aldine.

Smigel, Erwin O. 1964. The Wall Street Lawyer: Professional Organization Man? New York: Free Press.

Smith, John M. 1974. "Age and Occupation: A Review of the Use of Occupational Age Structures in Industrial Gerontology." Industrial Gerontology 1 (Spring): 42-58.

Sofer, Cyril. 1970. Men in Mid-Career: A Study of British Managers and Technical Specialists. Cambridge: Cambridge University Press.

Sørensen, Aage B. 1975. "The Structure of Intragenerational Mobility." American Sociological Review 40 (August): 456-71.

Spilerman, Seymour, and Jack Habib. 1976. "Development Towns in Israel: The Role of Community in Creating Ethnic Disparities in Labor Force Characteristics." American Journal of Sociology 81 (January): 781-812.

Spilerman, Seymour, and Richard E. Miller. 1973. "The Effect of Negative Tax Payments on Job Turnover and Job Selection." Chap. 7 in The Final Report of the New Jersey Graduated Work Incentive Experiment, edited by Harold W. Watts and Albert Rees. Vol. 1. Madison, Wis.: Institute for Research on Poverty.

Stewman, Shelby. 1975. "Two Markov Models of Open System Occupational Mobility: Underlying Conceptualizations and Empirical Tests." American Sociological Review 40 (June) : 298-321.

Stinchcombe, Arthur. 1959. "Bureaucratic and Craft Administration of Production: A Comparative Study." Administrative Science Quarterly 4 (September): 168-87. 
—. 1964. "Social Structure and Organizations." Pp. 142-93 in Handbook of Organizations, edited by James March. Chicago: Rand McNally.

Stolzenberg, Ross M. 1975. "Occupations, Labor Markets and the Process of Wage Attainment." American Sociological Review 40 (October): 645-65.

Super, Donald E. 1957. The Psychology of Careers. New York: Harper.

Taylor, Lee. 1968. Occupational Sociology. New York: Oxford University Press.

Temme, Lloyd V. 1975. Occupation: Meanings and Measures. Washington, D.C.: Bureau of Social Science Research.

Thompson, James D., Robert W. Avery, and Richard O. Carlson. 1968. "Occupations, Personnel, and Careers." Educational Administration Quarterly 4:6-31.

Thurow, Lester C. 1975. Generating Inequality. New York: Basic.

U.S. Bureau of the Census. 1973. 1970 Census of Population. Vol. 1. Characteristics of the Population. Washington, D.C.: Government Printing Office.

Vietorisz, Thomas, and Bennett Harrison. 1973. "Labor Market Segmentation: Positive Feedback and Divergent Development." American Economic Review 63 (May): 366-76.

Walker, Charles, and Robert Guest. 1952. The Man on the Assembly Line. Cambridge, Mass.: Harvard University Press.

Wilensky, Harold L. 1960. "Work, Careers, and Social Integration." International Social Science Journal 12 (Fall): 543-60.

- 1961. "Orderly Careers and Social Participation: The Impact of Work History on Social Integration in the Middle Mass." American Sociological Review 26 (August) : 521-39.

Wilson, James Q. 1968. Varieties of Police Behavior. Cambridge, Mass.: Harvard University Press.

Woodward, Joan. 1965. Industrial Organization: Theory and Practice. London: Oxford University Press. 